\title{
A modified band approach for the accurate calculation of online photolysis rates in stratospheric-tropospheric Chemical Transport Models
}

\author{
J. E.Williams ${ }^{1}$, J. Landgraf ${ }^{2}$, A. Bregman ${ }^{1}$, and H. H. Walter ${ }^{2}$ \\ ${ }^{1}$ Royal Netherlands Meteorological Institute, De Bilt, The Netherlands \\ ${ }^{2}$ SRON National Institute for Space Research, Utrecht, The Netherlands
}

Received: 16 January 2006 - Published in Atmos. Chem. Phys. Discuss.: 5 May 2006

Revised: 15 August 2006 - Accepted: 15 September 2006 - Published: 19 September 2006

\begin{abstract}
Here we present an efficient and accurate method for the online calculation of photolysis rates relevant to both the stratosphere and troposphere for use in global Chemistry Transport Models and General Circulation Models. The method is a modified version of the band model introduced by Landgraf and Crutzen (1998) which has been updated to improve the performance of the approach for solar zenith angles $>72^{\circ}$ without the use of any implicit parameterisations. For this purpose, additional sets of band parameters have been defined for instances where the incident angle of the light beam is between $72-93^{\circ}$, in conjunction with a scaling component for the far UV region of the spectrum $(\lambda=178.6-$ $202.0 \mathrm{~nm})$. For incident angles between $85-93^{\circ}$ we introduce a modification for pseudo-sphericity that improves the accuracy of the 2-stream approximation. We show that this modified version of the Practical Improved Flux Method (PIFM) is accurate for angles $<93^{\circ}$ by comparing the resulting height resolved actinic fluxes with a recently developed full spherical reference model. We also show that the modified band method is more accurate than the original, with errors generally being less than $\pm 10 \%$ throughout the atmospheric column for a diverse range of chemical species. Moreover, we perform certain sensitivity studies that indicate it is robust and performs well over a wide range of conditions relevant to the atmosphere.
\end{abstract}

\section{Introduction}

The incidence of photolysing light on the Earth's atmosphere acts as the principle driving force for many important chemical reaction cycles, which, in turn, play a crucial role to-

Correspondence to: J. E.Williams

(williams@knmi.nl) wards determining the overall chemical composition of the atmosphere by governing the lifetimes of many key greenhouse species. Many trace gas species exhibit photodissociative rate coefficients $\left(J_{x}\right)$, which can be calculated by integrating the product of the absorption co-efficient $\left(\sigma_{x}\right)$, the quantum yield $\left(\phi_{x}\right)$ and the (spectral) actinic flux $\left(F_{\text {act }}\right)$ over all wavelengths, as described by Eq. (1):

$J_{x}=\int \sigma_{x}(\lambda) \phi_{x}(\lambda) F_{a c t}(\lambda) d \lambda$

Where both $\sigma_{x}$ and $\phi_{x}$ are characteristic for each specific chemical species $(X)$ and maybe dependent on temperature. $F_{\text {act }}$ varies with both height and wavelength, and is principally governed by many atmospheric properties, such as the solar geometry, the reflection properties of the Earth's surface, the vertical distribution of ozone, clouds and aerosols and their microphysical properties.

For any model whose aim is to simulate the chemical processes which occur in the atmosphere an important prerequisite is the inclusion of an accurate code for the calculation of such $J$ rates. Moreover, it is vital that the sphericity of the atmosphere and increased scattering of the incident beam is accounted for during instances of low sun, as this has a direct impact on the magnitude of such rates. Recently, Trentmann et al. (2003) have shown that refraction of light at high solar zenith angles (hereafter referred to as $\theta$ ) in the upper stratosphere can significantly increase photolysis frequencies by up to $100 \%$ in the visible region of the spectrum, which leads to substantial changes in twilight concentrations of many key species. Moreover, using a more complex chemistry-climate model, Lamago et al. (2003) conclude that the depth and extent of ozone destruction simulated for the southern hemisphere is affected by the photolytic production of $\mathrm{ClO}$ at the end of the polar winter (where $87.5^{\circ}<\theta<93^{\circ}$ ). For global 3-D Chemistry Transport Models (CTM's), where

Published by Copernicus GmbH on behalf of the European Geosciences Union. 
the calculation of $J$ values is mandatory, there is also the requirement of computational efficiency, which often requires the use of fast and concise methods in which to calculate $J$ values, thus avoiding excessive runtimes. Therefore, rather than using an infinite number of points which cover the entire spectral range it is necessary to introduce a spectral grid which divides the spectral range into a finite number of bins onto which $\sigma$ and $\phi$ values maybe interpolated (e.g. Brühl and Crutzen, 1988; Kylling et al., 1995). However, solving the radiative transfer equation for each spectral bin individually is still prohibitively expensive, even when using the fastest super-computers, which necessitates the use of further parameterisations. Thus, values of $F_{\text {act }}$ are commonly calculated offline in many CTM's. These $F_{\text {act }}$ values are usually derived using standard atmospheres under clear-sky conditions, meaning that in many instances, the effect of clouds and aerosols on photolysis rates is not accounted for accurately. Such values are often stored as offline look-up tables which are indexed using atmospheric parameters such as the $\theta$, temperature, pressure, the concentration of overhead $\mathrm{O}_{3}$ and geometric height (e.g. Brasseur et al., 1998; Kouker et al., 1999; Bregman et al., 2000). However, such an approach can be rather inflexible if regular updates are needed to input parameters such as absorption coefficients, where the recalculation of large look-up tables is often undesirable.

Recently several different methods have been developed which avoid the sole use of look-up tables by performing the online calculation of $F_{\text {act }}$ during each time step in the CTM. Generally, this is made feasible by introducing a much coarser wavelength grid meaning that only a limited number of calculations are needed. For example, Wild et al. (2000) describe the use of an 8-stream radiative transfer (RT) solver in conjunction with 7 wavelength bins $(\lambda=289-850 \mathrm{~nm})$, in addition to approximations for both single and multiple scattering, for the fast online calculation of $J$ values relevant to the troposphere. This has recently been extended to account for the spectral range relevant to the stratosphere, where a total of 18 wavelength bins are used for the entire spectral range $(\lambda=177-850 \mathrm{~nm})$, with the first 11 being opacity-sorted so as to accurately describe the mean radiation field between 177-291 nm and with Rayleigh scattering being described as a pseudo-absorption (Bian and Prather, 2002). Another example is the recently developed Fast Tropospheric Ultraviolet-Visible model (FTUV) code, which is based on the Tropospheric Ultraviolet-Visible model (TUV) RT model developed by Madronich (1987) and uses a modified wavelength grid between $121-850 \mathrm{~nm}$, where the number of spectral bins is reduced from 140 to 17 (Tie et al., 2004). However, this method is specifically developed for photolysis rates important in the troposphere and therefore was not tuned for species such as $\mathrm{N}_{2} \mathrm{O}$ and $\mathrm{O}_{2}$. The calculation of tropospheric $J$ values is critically dependent on the number of wavelength bins used, where Madronich and Weller (1990) have shown that more than 100 bins are needed to achieve acceptable errors. Therefore, $J$ values calculated by FTUV still need to have a correction function applied which is dependent on the concentration of overhead $\mathrm{O}_{3}, \theta$ and temperature and stored as an offline look-up table.

In this paper we introduce a method for the online calculation of $J$ values relevant to both the troposphere and stratosphere without the use of look-up tables for $F_{\text {act }}$, which can easily be implemented into a state-of-the-art CTM. The method is based on the band approach originally developed by Landgraf and Crutzen (1998), which has been expanded in order to improve the accuracy at high solar zenith angles (hereafter referred to as the modified band approach). For this purpose we have defined additional sets of the band parameters which are used for incident $\theta>72^{\circ}$, as well as implementing an additional scaling ratio for the far ultra-violet (UV) region of the spectrum. The explicit nature of this modified approach means that the parameterisation of $J_{\text {abs }}$ as a function of the slant path of the total overhead $\mathrm{O}_{3}$ and $\mathrm{O}_{2}$, as described in Landgraf and Crutzen (1998), is no longer needed. This makes the method fully transparent and allows updates/additional photolysis reactions to be added quickly so that the code can potentially fit a host of lumped and explicit chemical reaction schemes.

This paper is arranged as follows: in Sect. 2 we summarise the basic concept of the band approach and outline the assumptions made during the calculation of $J$ values. In Sect. 3 we discuss the motivation and details of the four modifications that have been introduced into the original band approach to improve performance for high solar zenith angles. In Sect. 4 we assess the performance of the modified band approach and make direct comparisons with results obtained using the original method. We also examine the robustness of the approach by testing over a range of different atmospheric conditions. Section 5 provides further discussion regarding the performance for an expanded set of $J$ values, suggestions regarding the implementation of the scheme into other models and a brief analysis of the associated computational expense. Finally, in Sect. 6 we present our concluding remarks.

\section{The original band approach}

In this section we provide a summary of the basic concept behind the modified band approach. In the interests of brevity we simply outline the general approach and for further detail the reader is referred to the more in-depth discussion provided by Landgraf and Crutzen (1998) regarding errors associated with the original method. The spectral grid of Brühl and Crutzen (1988), which covers the spectral range $\lambda=178.6-752.5 \mathrm{~nm}$, is sub-divided into 8 distinct bands and the contributions by each band to each individual photolysis rate is calculated separately (for details of the band limits see Table 1). Calculations are only performed for bands contributing to the photodissociation of a certain species as dictated by the absorption characteristics of that species. Due to 
Table 1. Wavelengths chosen for the lower and upper band limits, and for the derivation of scaling ratios $\left(\delta_{i}\right)$ in the operational version of the modified band approach. Values for $\theta<72^{\circ}$ are taken from Landgraf and Crutzen (1998) and those for $\theta=72-85^{\circ}(\mathrm{A})$ and $\theta=85-93^{\circ}$ (B) as derived in this study.

\begin{tabular}{cccccccccc}
\hline Band & $\lambda_{\min }$ & $\lambda_{\max }$ & $\lambda_{\text {scale }}$ & $\lambda_{\min }(\mathrm{A})$ & $\lambda_{\max }(\mathrm{A})$ & $\lambda_{\text {scale }}(\mathrm{A})$ & $\lambda_{\min }(\mathrm{B})$ & $\lambda_{\max }(\mathrm{B})$ & $\lambda_{\text {scale }}(\mathrm{B})$ \\
\hline 1 & 178.6 & 202.0 & N/A & 178.6 & 202.0 & 199.0 & 178.6 & 202.0 & 201.0 \\
2 & 202.0 & 241.0 & 205.1 & 202.0 & 243.9 & 209.4 & 202.0 & 243.9 & 213.9 \\
3 & 241.0 & 289.8 & 287.7 & 243.9 & 289.8 & 287.7 & 243.9 & 289.8 & 287.7 \\
4 & 289.8 & 305.5 & 302.0 & 289.8 & 305.5 & 302.0 & 289.8 & 305.5 & 302.0 \\
5 & 305.5 & 313.5 & 309.0 & 305.5 & 313.5 & 311.0 & 305.5 & 312.5 & 311.0 \\
6 & 313.5 & 337.5 & 320.0 & 313.5 & 347.5 & 326.5 & 312.5 & 357.5 & 345.0 \\
7 & 337.5 & 422.5 & 370.0 & 347.5 & 482.5 & 385.0 & 357.5 & 492.5 & 410.0 \\
8 & 422.5 & 752.5 & 580.0 & 482.5 & 752.5 & 610.0 & 492.5 & 752.5 & 610.0 \\
\hline
\end{tabular}

the strong absorption by $\mathrm{O}_{2}$ in the spectral range $\lambda=178.6-$ $202.0 \mathrm{~nm}$, the contribution to $F_{\text {act }}$ by scattering in this spectral range is assumed to be negligible for $\theta<72^{\circ}$. However, for $\lambda \geq 202 \mathrm{~nm}$, the scattering by gaseous molecules can make a significant contribution to $F_{\text {act }}$ and, therefore, must be accounted for. Moreover, for $\lambda \geq 300 \mathrm{~nm}$ the scattering contribution made by both aerosols and clouds must also be accounted for. Landgraf and Crutzen (1998) have shown that the $J$ value for species $X$ may be approximated by multiplying the $J_{\text {abs }}$ value, calculated in a non-scattering atmosphere, by a scaling ratio:

$\delta_{i}=\frac{F_{\mathrm{act}}\left(\lambda_{i}\right)}{F_{\mathrm{abs}}\left(\lambda_{i}\right)}$

at a specific wavelength $\left(\lambda_{i}\right)$ within the band limits for band $(i)$. Here $F_{\text {act }}\left(\lambda_{i}\right)$ is the actual actinic flux at $\lambda_{i}$ and $F_{\text {abs }}\left(\lambda_{i}\right)$ the actinic flux for a non-scattering atmosphere at $\lambda_{i}$. For the accurate derivation of $F_{\text {act }}$ in any chosen model atmosphere both the single and multiple scattering components of the incident light have to be taken into account. For this purpose several numerical methods are currently available which provide an accurate solution to the radiative transfer problem, where many use a multiple-stream approximation of the diffuse intensity field (e.g. Lenoble, 1985). Although such methods are commonly employed for the simulation of accurate photolysis rates in lower scale models, their use in CTM's is limited due to the numerical effort which is needed being rather expensive. For this reason the original band approach of Landgraf and Crutzen (1998) is commonly used in conjunction with a two-stream RT solver using a plane parallel geometry of the model atmosphere when applied for calculating photolysis rates (e.g. Lawrence et al., 1999).

Equation (3) describes $F_{\text {abs }}(\lambda)$, which is calculated for each individual wavelength bin assuming the transmission of light adheres to Lambert-Beer's law. Therefore, it is dependent on the slant column depth due to both absorbance by $\mathrm{O}_{3}$ and $\mathrm{O}_{2}\left(\tau_{\text {slant }}(\lambda)\right)$, with $F_{0}(\lambda)$ being the spectral solar irradiance at the top of the atmosphere. The absorption due to other trace gases (e.g. $\mathrm{NO}_{2}$ ), aerosols and clouds is assumed to be negligible compared to that of $\mathrm{O}_{2}$ and $\mathrm{O}_{3}$ and is therefore ignored.

$F_{\text {abs }}(\lambda)=F_{0}(\lambda) e^{-\tau_{\text {slant }}(\lambda)}$

For a plane parallel geometry the slant optical depth $\left(\tau_{\text {slant }}\right.$ ( $\lambda$ ) ) can be calculated using the density profile $\rho_{\mathrm{O}_{2}}$ and $\rho_{\mathrm{O}_{3}}$ of oxygen and ozone and their associated absorption crosssections $\sigma_{\mathrm{O}_{2}}$ and $\sigma_{\mathrm{O}_{3}}$ :

$\tau_{\text {slant }}(\lambda)=\frac{1}{\mu_{o}} \sum_{x=\mathrm{O}_{3}, \mathrm{O}_{2}} \int_{o}^{z_{\mathrm{TOA}}} \rho_{x} \sigma(\lambda)_{x} d z$

where $\mu 0$ is the cosine of the solar zenith angle and TOA is the top of the atmosphere. This resulting $F_{\text {abs }}(\lambda)$ is then used for the calculation of $J_{\text {abs }}$, whose cumulative sum within a band $(i)$ is subsequently scaled by $\delta_{i}$ for the determination of $J_{i}$. The scaling ratio $\left(\delta_{i}\right)$ need only be calculated for one specific wavelength bin in each of the bands 2-8 and, thus, the full solution of the radiative transfer equation only needs to be performed for a total of 7 distinct wavelength bins. This makes the approach very efficient, as the most computationally expensive step in the derivation of $F_{\text {act }}$ is the calculation of the scattering component. The $J_{x}$ value is then calculated by summing all $J_{i}$ values for species $X$ for all bands:

$J_{x}=J_{1, x}^{\mathrm{abs}}+\sum_{i=2}^{8} J_{i, X}^{\mathrm{abs}} \delta_{i}$

The main assumption used in the band model is that the $F_{\text {act }}$ in each spectral band scales linearly with the corresponding flux for a non-scattering atmosphere. The scaling wavelengths are chosen such that the errors made at shorter wavelengths cancel out with errors made at longer wavelengths for a chosen band i.e. the cumulative integral of all errors within such a band interval is approximately zero. In addition biases in the individual band contribution can cancel out due to the summation in Eq. (5). This approach works very well for $\theta<75^{\circ}$, as demonstrated by Landgraf and Crutzen (1998). 


\section{The modified band approach}

In order to extend the original band approach for low sun geometry four main modifications have been applied to the existing scheme, as follows: (1) the radiative transfer model has to be extended to account for the spherical shape of the model atmosphere. For this purpose we introduce a pseudo-spherical extension of a two-stream method, where the sphericity is only accounted for in the calculation of the direct light component. The diffuse component of the radiation field is still considered in plane parallel geometry. (2) A limit is applied to the scaling ratios $\left(\delta_{i}\right)$ for instances where $F_{\text {abs }}$ falls below a selected threshold value. (3) A scaling ratio is introduced for the first band $(\lambda \leq 202 \mathrm{~nm})$ taking into account the scattering of radiation in the upper part of the model atmosphere. (4) Due to the increase of the slant optical depth $\left(\tau_{\text {slant }}\right)$ in instances of low sun, the maximum amount of radiation per band interval is shifted towards wavelengths of weaker absorption. Therefore, for high incident angles the selection of the scaling wavelengths $\left(\lambda_{i}\right)$ and band limits have been further optimized.

\subsection{The model atmosphere and spectroscopic data}

The development and testing of the modified band approach was performed using a standard one-dimensional column model atmosphere. The vertical grid consisted of 80 equidistant layers of $1 \mathrm{~km}$ depth from the ground level to the top of the atmosphere. The pressure, temperature, relative humidity and $\mathrm{O}_{3}$ concentrations were taken directly from the U.S. standard atmosphere (NOAA, 1976) and interpolated onto the vertical grid. The total ozone column is scaled to $300 \mathrm{DU}$ to allow direct comparisons with the results presented in Landgraf and Crutzen (1998). The slant column for each layer/level combination is calculated in a similar manner to that documented by Madronich (1987) and is imperative for the correct $F_{\mathrm{abs}}$ values in the lowest layers (and thus scaling ratios). The ground was treated as a Lambertian reflector using fixed albedo values of 5\% unless stated otherwise, with the value of the albedo being fixed across the entire spectral range.

Table 2 provides a comprehensive list of all of the photodissociation rates which have been examined during the testing phase. The characteristic absorption co-efficients $\left(\sigma_{x}\right)$ and quantum yields $\left(\phi_{x}\right)$ for each chemical species (X) were taken from the latest recommendations (e.g. Sander et al., 2003; Atkinson et al., 2004) and subsequently interpolated onto the working spectral grid of Brühl and Crutzen (1988), where 142 spectral bins are used between 178.6$752.5 \mathrm{~nm}$ (of varying resolution). The number of photolysis rates added for stratospheric species has been significantly increased compared to the original treatise of Landgraf and Crutzen (1998) meaning that the performance of the both the original and modified band method is being tested for such compounds for the first time (e.g. BrO).
To avoid an exhaustive analysis involving all 38 photolysis reactions for which the approach was tested, we define two smaller subsets of the species with each subset being photolytically relevant to either the stratosphere or the troposphere, as defined in Table 3. One of the conditions involved in the selection of these two chemical subsets was that the absorption behavior was sufficiently diverse enough to be able to test the modified band method across the entire spectral range.

For molecular $\mathrm{O}_{2}$ the absorption in the Lyman-Alpha and Schumann-Runge regions of the spectrum are accounted for using the parameterizations of Chabrillat and Kockarts (1997) and Koppers and Murtagh (1996), respectively. For the photolysis of NO, which occurs in the far UV, the parameterization of Allen and Frederick (1982) is implemented. Temperature dependencies of $\sigma$ values are included for 18 of the chosen chemical species (see Table 2). Moreover, a temperature dependency for the $\phi$ related to $\mathrm{O}^{1} \mathrm{D}$ production from the photolysis of $\mathrm{O}_{3}$ was also included as recommended by Matsumi et al. (2002). For the calculation of the Rayleigh scattering cross-sections the empirical approach of Nicolet (1984) is used. To treat aerosols in the model atmosphere we use the optical properties described by Shettle and Fenn (1979) for a rural, urban, maritime and a tropospheric background aerosol. The vertical distribution is adopted from McClatchey et al. (1972). The contribution of both absorption and scattering introduced by cloud layers is calculated using the parameterization of Slingo (1979). The model also allows one to take partial cloud coverage into account in the radiative transfer calculations using the approach of Geleyn and Hollingsworth (1979).

\subsection{Spherical radiative transfer}

To solve the spherical radiative transfer problem we consider a planetary atmosphere composed of homogeneous spherical shells. The atmosphere is illuminated symmetrically by parallel solar beams. Ignoring thermal emission and refract ional effects of radiation, the scalar $R T$ equation is given by Eq. (6), (Chandrasekar, 1960; Goody and Yung, 1989):

$\frac{d I}{d s}=-\beta_{\text {ext }} I+J_{\text {scat }}(I)$

where the spectral intensity $I$ is a function of position $\boldsymbol{r}$ and direction $\boldsymbol{\Omega}$. $\beta_{\text {ext }}$ represents the extinction coefficient, which due to the symmetry of the model atmosphere depends only on the radius $|\boldsymbol{r}|$. Furthermore the scattering source function $J_{\text {scat }}$ depends itself on the intensity field $I . \frac{d}{d s}$ is the derivative along the pathlength $s$ in the direction $\boldsymbol{\Omega}$. Given the solution $I$, the actinic flux can be calculated by the solid angle integration:

$F_{\text {act }}(\boldsymbol{r})=\int_{4 \pi} d \Omega I(\boldsymbol{r}, \boldsymbol{\Omega})$,

where $\Omega$ represents the solid angle. 
Table 2. Details concerning the literature values adopted for the characteristic absorption co-efficients and quantum yields for all photolytically active chemical species evaluated in this study, where $(*)$ denotes temperature dependent absorption parameters. A value of unity is assumed for the quantum yields of species where there is a lack of laboratory data. Reactions highlighted in red are those for which limits are applied to the $\delta$ ratios for band intervals 2 and 4 once $\theta>81^{\circ}$. For $\theta>85^{\circ}$ limits are applied to all chemical species in order to avoid problems in the middle atmosphere.

\begin{tabular}{|c|c|c|}
\hline Photolysis reaction & Absorption co-efficient & Quantum Yield \\
\hline $\mathrm{O}_{2} \stackrel{h v}{\longrightarrow} \mathrm{O}^{3} \mathrm{P}+\mathrm{O}^{3} \mathrm{P}$ & $\begin{array}{l}\text { Chabrilla and Kockarts (1994) } \\
(\lambda=121-123 \mathrm{~nm}) \\
\text { Koppers and Murtagh (1996) } \\
(\lambda=178.6-202 \mathrm{~nm}) \\
\text { Sander et al. }(2003) \\
(\lambda>202 \mathrm{~nm})\end{array}$ & 1.0 \\
\hline $\mathrm{O}_{3} \stackrel{h v}{\longrightarrow} \mathrm{O}_{2}+\mathrm{O}^{1} \mathrm{D}$ & Molinda and Molinda (1986)* & Matsumi et al. $(2002)^{*}$ \\
\hline $\mathrm{O}_{3} \stackrel{h v}{\longrightarrow} \mathrm{O}_{2}+\mathrm{O}^{3} \mathrm{P}$ & Molinda and Molinda (1986)* & Matsumi et al. $(2002)^{*}$ \\
\hline $\mathrm{NO}_{2} \stackrel{h v}{\longrightarrow} \mathrm{NO}+\mathrm{O}^{3} \mathrm{P}$ & Sander et al. $(2003)^{*}$ & Sander et al. (2003) \\
\hline $\mathrm{NO}_{3} \stackrel{h v}{\longrightarrow} \mathrm{NO}+\mathrm{O}_{2}$ & Sander et al. $(2003)^{*}$ & Sander et al. (2003) \\
\hline $\mathrm{NO}_{3} \stackrel{h v}{\longrightarrow} \mathrm{NO}_{2}+\mathrm{O}^{3} \mathrm{P}$ & Sander et al. $(2003)^{*}$ & Sander et al. (2003) \\
\hline $\mathrm{N}_{2} \mathrm{O} \stackrel{h v}{\longrightarrow} \mathrm{N}_{2}+\mathrm{O}^{1} \mathrm{D}$ & Sander et al. (2003)* & 1.0 \\
\hline $\mathrm{N}_{2} \mathrm{O}_{5} \stackrel{h v}{\longrightarrow} \mathrm{NO}_{2}+\mathrm{NO}_{3}$ & Sander et al. (2003)* & 1.0 \\
\hline $\mathrm{H}_{2} \mathrm{O}_{2} \stackrel{h v}{\longrightarrow} 2 \mathrm{OH}$ & Sander et al. (2003)* & 1.0 \\
\hline $\mathrm{HNO}_{3} \stackrel{h v}{\longrightarrow} \mathrm{OH}+\mathrm{NO}_{2}$ & Sander et al. (2003)* & 1.0 \\
\hline $\mathrm{HNO}_{4} \stackrel{h v}{\longrightarrow} \mathrm{HO}_{2}+\mathrm{NO}_{2}$ & Sander et al. (2003) & 1.0 \\
\hline $\mathrm{CH}_{2} \mathrm{O} \stackrel{h v}{\longrightarrow} \mathrm{HCO}+\mathrm{H}$ & Sander et al. $(2003)^{*}$ & Sander et al. (2003) \\
\hline $\mathrm{CH}_{2} \mathrm{O} \stackrel{h v}{\longrightarrow} \mathrm{CO}+\mathrm{H}_{2}$ & Sander et al. $(2003)^{*}$ & Sander et al. (2003) \\
\hline $\mathrm{CH}_{3} \mathrm{CHO} \stackrel{h v}{\longrightarrow} \mathrm{CH}_{4}+\mathrm{CO}$ & Martinez et al. (1992) & Atkinson et al. (2004) \\
\hline $\mathrm{CH}_{3} \mathrm{COCHO} \stackrel{h v}{\longrightarrow} \mathrm{CH}_{3} \mathrm{CO}_{3}+\mathrm{CO}+\mathrm{HO}_{2}$ & Atkinson et al. (1997) & Koch and Moortgat (1998) \\
\hline $\mathrm{CH}_{3} \mathrm{COCH}_{3} \stackrel{h v}{\longrightarrow} \mathrm{CH}_{3} \mathrm{CO}_{3}+\mathrm{CH}_{3} \mathrm{O}_{2}$ & Atkinson et al. (1997) & McKeen et al. (1997) \\
\hline $\mathrm{CH}_{3} \mathrm{OOH} \stackrel{h v}{\longrightarrow} \mathrm{CH}_{3} \mathrm{O}+\mathrm{OH}$ & Sander et al. (2003) & 1.0 \\
\hline $\mathrm{CH}_{3} \mathrm{O}_{2} \mathrm{NO}_{2} \stackrel{h v}{\longrightarrow} \mathrm{CH}_{3} \mathrm{O}_{2}+\mathrm{NO}_{2}$ & Atkinson et al. (1997) & 1.0 \\
\hline PAN $\stackrel{h v}{\longrightarrow}$ Products & Sander et al. $(2003)^{*}$ & 1.0 \\
\hline $\mathrm{OClO} \stackrel{h v}{\longrightarrow} \mathrm{ClO}+\mathrm{O}^{3} \mathrm{P}$ & Sander et al. (2003) & 1.0 \\
\hline $\mathrm{ClNO}_{3} \stackrel{h v}{\longrightarrow} \mathrm{Cl}+\mathrm{NO}_{3}$ & Sander et al. $(2003)^{*}$ & Atkinson et al. (2004) \\
\hline $\mathrm{CH}_{3} \mathrm{Cl} \stackrel{h v}{\longrightarrow}$ Products & Sander et al. $(2003)^{*}$ & 1.0 \\
\hline $\mathrm{CCl} 4 \stackrel{h v}{\longrightarrow}$ Products & Sander et al. $(2003)^{*}$ & 1.0 \\
\hline $\mathrm{CF}_{2} \mathrm{ClCFCl}_{2} \stackrel{h v}{\longrightarrow}$ Products & Sander et al. (2003)* & 1.0 \\
\hline $\mathrm{CCl}_{3} \mathrm{~F} \stackrel{h v}{\longrightarrow}$ Products & Sander et al. (2003)* & 1.0 \\
\hline $\mathrm{CCl}_{2} \mathrm{~F}_{2} \stackrel{h v}{\longrightarrow}$ Products & Sander et al. (2003)* & 1.0 \\
\hline $\mathrm{BrNO}_{3} \stackrel{h v}{\longrightarrow} \mathrm{Br}+\mathrm{NO}_{3}$ & Sander et al. (2003) & 1.0 \\
\hline $\mathrm{CH}_{3} \mathrm{Br} \stackrel{h v}{\longrightarrow}$ Products & Sander et al. $(2003)^{*}$ & 1.0 \\
\hline $\mathrm{BrCl} \stackrel{h v}{\longrightarrow} \mathrm{Br}+\mathrm{Cl}$ & Sander et al. $(2003)^{*}$ & 1.0 \\
\hline $\mathrm{HCl} \stackrel{h v}{\longrightarrow} \mathrm{H}+\mathrm{Cl}$ & Sander et al. (2003) & 1.0 \\
\hline $\mathrm{HOCl} \stackrel{h v}{\longrightarrow} \mathrm{OH}+\mathrm{Cl}$ & Sander et al. (2003) & 1.0 \\
\hline $\mathrm{HOBr} \stackrel{h v}{\longrightarrow} \mathrm{OH}+\mathrm{Br}$ & Sander et al. (2003) & 1.0 \\
\hline $\mathrm{BrO} \stackrel{h v}{\longrightarrow} \mathrm{Br}+\mathrm{O}^{3} \mathrm{P}$ & Sander et al. (2003)* & 1.0 \\
\hline $\mathrm{Cl}_{2} \mathrm{O}_{2} \stackrel{h v}{\longrightarrow} \mathrm{Cl}+\mathrm{ClO}_{2}$ & Sander et al. (2003) & 1.0 \\
\hline $\mathrm{H}_{2} \mathrm{O} \stackrel{h v}{\longrightarrow} \mathrm{H}+\mathrm{OH}$ & Sander et al. (2003) & 1.0 \\
\hline $\mathrm{CO}_{2} \stackrel{h v}{\longrightarrow} \mathrm{CO}+\mathrm{O}^{3} \mathrm{P}$ & Schemansky (1972) & 1.0 \\
\hline $\mathrm{NO} \stackrel{h v}{\longrightarrow} \mathrm{N}+\mathrm{O}^{3} \mathrm{P}$ & Allen and Frederick (1982) & 1.0 \\
\hline
\end{tabular}


Table 3. Definitions of the tropospheric and stratospheric chemical subsets selected for the derivation of the low sun band settings and the analysis of the performance of the modified band approach. The spectral range indicates the spectral region over which each species exhibits absorption.

\begin{tabular}{llll}
\hline \multicolumn{2}{c}{ Troposphere } & \multicolumn{2}{c}{ Stratosphere } \\
Photolysis reaction & Spectral range [nm] & Photolysis reaction & Spectral range [nm] \\
\hline $\mathrm{O}_{3} \stackrel{h v}{\longrightarrow} \mathrm{O}_{2}+\mathrm{O}^{1 D}$ & $219.8-342.5$ & $\mathrm{~N}_{2} \mathrm{O} \stackrel{h v}{\longrightarrow} \mathrm{N}_{2}+\mathrm{O}^{1 D}$ & $178.6-241.0$ \\
$\mathrm{NO}_{2} \stackrel{h v}{\longrightarrow} \mathrm{NO}+\mathrm{O}^{3 P}$ & $202.0-422.5$ & $\mathrm{OClO} \stackrel{h v}{\longrightarrow} \mathrm{ClO}+\mathrm{O}^{3 P}$ & $259.7-477.5$ \\
$\mathrm{~N}_{2} \mathrm{O}_{5} \stackrel{h v}{\longrightarrow} \mathrm{NO}_{2}+\mathrm{NO}_{3}$ & $178.6-382.5$ & $\mathrm{Cl}_{2} \mathrm{O}_{2} \stackrel{h v}{\longrightarrow} \mathrm{Cl}+\mathrm{ClO}_{2}$ & $178.6-452.5$ \\
$\mathrm{HNO}_{3} \stackrel{h v}{\longrightarrow} \mathrm{OH}+\mathrm{NO}_{2}$ & $178.6-352.5$ & $\mathrm{ClNO}_{3} \stackrel{h v}{\longrightarrow} \mathrm{Cl}+\mathrm{NO}_{3}$ & $196.1-422.5$ \\
$\mathrm{HNO}_{4} \underset{h v}{\longrightarrow} \mathrm{HO}_{2}+\mathrm{NO}_{2}$ & $178.6-327.9$ & $\mathrm{BrNO}_{3} \stackrel{h v}{\longrightarrow} \mathrm{Br}+\mathrm{NO}_{3}$ & $178.6-497.5$ \\
$\mathrm{H}_{2} \mathrm{O}_{2} \stackrel{h v}{\longrightarrow} 2 \mathrm{OH}$ & $178.6-347.5$ & $\mathrm{BrO} \stackrel{h v}{\longrightarrow} \mathrm{Br}+\mathrm{O}^{3 P}$ & $311.5-392.5$ \\
$\mathrm{CH}_{2} \mathrm{O} \stackrel{h v}{\longrightarrow} \mathrm{HCO}+\mathrm{H}$ & $298.1-347.5$ & $\mathrm{CCl}_{2} \mathrm{~F}_{2} \stackrel{h v}{\longrightarrow} \mathrm{Products}$ & $178.6-241.0$ \\
$\mathrm{CH}_{2} \mathrm{O} \stackrel{h v}{\longrightarrow} \mathrm{CO}+\mathrm{H}_{2}$ & $298.1-357.5$ & $\mathrm{BrCl} \stackrel{h v}{\longrightarrow} \mathrm{Br}+\mathrm{Cl}$ & $200.0-602.5$ \\
\hline
\end{tabular}

The spherical radiative transfer equation, as given in Eq. (6), represents a differential equation for three spatial parameters. It can be solved by integration along a representative set of the characteristic lines. In turn the intensity field (I) can be determined using a Picard iteration scheme. However, for the three-dimensional spatial problem a large number of characteristic lines are needed, which hampers any numerical implementation. Here Rozanov et al. (2001) and Doicu et al. (2005) have shown that the number of characteristic lines can be reduced significantly using the symmetries of the model atmosphere and the solar illumination. In this study we utilize as a reference the model of Walter et al. ${ }^{1}$, which is based on this solution concept. The model has been verified with comparisons made against Monte Carlo simulations for the reflected intensity field and has shown an agreement of better than $2 \%$ employing in total $2.4 \times 10^{5}$ characteristic lines. For the actinic flux within the atmosphere we expect a similar or even higher accuracy.

For the numerical implementation of an algorithm to calculate photolysis rates in a CTM we are heavily restricted by the computational burden which RT schemes introduce. For this reason we have chosen the RT solver called PIFM (Practical Improved Flux Method), which was originally derived by Zdunkowski et al. (1980) and uses a two-stream approximation for calculating the diffuse components of $F_{\text {act }}$. The generalized two-steam approximation of scalar radiative transfer, in its plane parallel geometry, may be expressed by Zdunkowski et al. (1980):

$$
\frac{1}{\beta_{\mathrm{ext}}} \frac{d F^{+}}{d z}=\alpha_{1} F^{+}-\alpha_{2} F^{-}-\alpha_{3} I_{o}
$$

\footnotetext{
${ }^{1}$ Walter, H.H., Landgraf, J., Spada, F., and Doicu, A., Linearization of a radiative transfer model in spherical geometry, J. Geophys. Res., submitted, 2006.
}

$\frac{1}{\beta_{\mathrm{ext}}} \frac{d F^{-}}{d z}=\alpha_{2} F^{+}-\alpha_{1} F^{-}+\alpha_{4} I_{o}$

$\frac{\mu_{o}}{\beta_{\text {ext }}} \frac{d I_{o}}{d z}=I_{o}$

Where $F^{+}$and $F^{-}$are the upward and downward fluxes and $I_{O}$ describes the direct solar intensity, $\mathrm{z}$ represents the altitude, and the coefficients $\alpha_{1}$ to $\alpha_{4}$ are given by:

$\alpha_{1}=U\left(1-\omega\left(1-\beta_{o}\right)\right)$
$\alpha_{2}=U \beta_{o} \omega$
$\alpha_{3}=\omega \beta\left(\mu_{o}\right)$
$\alpha_{4}=(1-\omega) \beta\left(\mu_{o}\right)$.

Here $U$ is the diffusivity factor, $\omega$ is the single scattering albedo, $\beta_{o}$ is the fractional mean backward scattering coefficient and $\beta\left(\mu_{o}\right)$ is the backward scattering coefficient of the direct solar beam. The values for the diffusivity factor and the backscattering coefficients depend on the particular twostream approximation. The PIFM RT solver (Zdunkowski et al., 1980) utilizes the following parameters:

$U=2$

$\beta_{o}=\frac{3-p_{1}}{8}$

$\beta\left(\mu_{o}\right)=\frac{1}{2}-\frac{\mu_{o}}{4} p_{1}$

where $p_{1}$ is first coefficient of an expansion of the scattering phase function in terms of Legendre polynomials. 
Equations (8-10) can be solved by using standard methods for a vertically inhomogeneous atmosphere which is subdivided into a number of homogenous layers. Using the solution for $F^{+}, F^{-}$and $I_{o}$, the actinic flux can be approximated by:

$F_{\text {act }}=U\left(F^{+}+F^{-}\right)+I_{o}$.

To take into account effects of the Earth sphericity on the radiative transfer one can use, as a first correction to the plane parallel approach, the air mass of a spherical model atmosphere for the attenuation of the direct beam. Therefore we modify the air mass factor $\left(\mu_{o}^{-1}\right)$ in Eq. $(10)$ by a corresponding expression suggested by Kasten and Young (1989);

$f(\gamma)=\frac{1}{\sin \gamma+a(\gamma+b)^{-c}}$

Where $\gamma$ is the solar elevation angle and values for the empirical constants of $a=0.5057, b=6.08^{\circ}$, and $c=1.636$. We hereafter refer to this version of the solver as PIFM-KY.

A more sophisticated method of representing sphericity is the pseudo-spherical approximation (e.g. Caudill et al., 1997; Rozanov et al., 2000; Spur et al., 2001; Walter et al., 2004). Here the Lambert-Beers absorption law of the direct beam in Eq. (10) is replaced by a corresponding equation for spherical geometry:

$\frac{d I_{o}}{d s}=-\beta_{\mathrm{ext}} I_{o}$

with $s$ being the path length of the direct beam through a spherical atmosphere with respect to the global zenith angle. Figure 1 shows the slant path of the direct beam as it travels through such a spherical atmosphere. By solving this equation, the direct light can be coupled into the flux equation of a plane parallel atmosphere via Eqs. (6) and (7). For $\theta>90^{\circ}$, one has to bear in mind that the solar beam does not illuminate the upper boundary of a particular atmospheric layer anymore but its lower boundary. In turn we have to modify the coefficients $\alpha_{3}$ and $\alpha_{4}$ in Eqs. (8) and (9), accordingly:

$\alpha_{3}=\left[\Theta\left(\mu_{o}\right) \omega+\Theta\left(-\mu_{o}\right)(1-\omega)\right] \beta\left(\mu_{o}\right)$

$\alpha_{4}=\left[\Theta\left(-\mu_{o}\right)(1-\omega)+\Theta\left(\mu_{o}\right) \omega\right] \beta\left(\mu_{o}\right)$

where $\Theta$ is the Heaviside step function. These modified flux equations can subsequently be solved using the method described by Zdunkowski et al. (1980). We hereafter refer to this version of the solver as PIFM-PS.

To give an estimate regarding the accuracy of both PIFMKY and PIFM-PS, we have compared simulations of the actinic flux with those calculated using the spherical reference model (hereafter referred to as reference model A). Figures $2 \mathrm{a}$ and $\mathrm{b}$ show the percentage differences in $F_{\text {act }}$ obtained when comparing the plane parallel PIFM model, PIFM-KY and PIFM-PS with reference model A at $\lambda=326.5 \mathrm{~nm}$ and $\lambda=610 \mathrm{~nm}$, respectively. For $\theta<70^{\circ}$, the different versions of PIFM provide almost identical results for

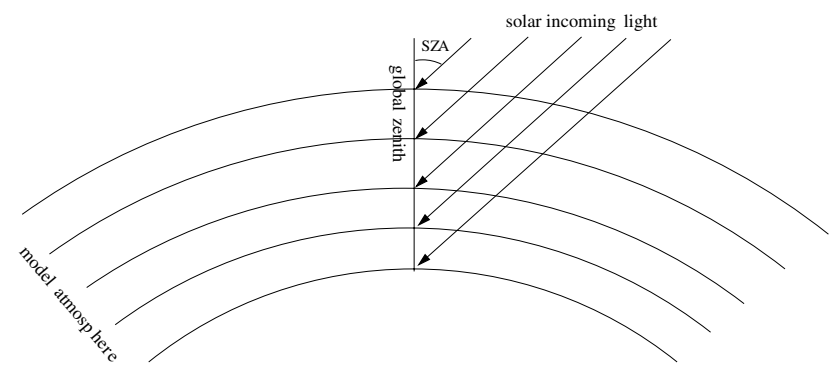

Fig. 1. Spherical geometry used for the pseudo spherical twostream method. The solar radiation is calculated at the global zenith along its spherical light path through the atmosphere and then it is used as the source of solar light in a plane parallel atmosphere.

the chosen altitude levels, where differences compared with the reference model never exceed 5\%. However, at $\theta>80^{\circ}$ the simple plane-parallel model clearly deviates from the modified versions of PIFM, with the largest errors occurring at the lower altitudes (cf. $60 \mathrm{~km}$ with $20 \mathrm{~km}$ ). Similar effects occur for $\theta>85^{\circ}$ using PIFM-KY. In contrast, these figures show that the pseudo spherical PIFM model provides very accurate estimates of the actinic flux up to $\theta=90^{\circ}$. It should be noted that PIFM-PS is much more computationally expensive than the PIFM-KY meaning that it's application is only warranted when the increase in accuracy is significant (i.e.) above $85^{\circ}$. Details relating to the computational expense of each version of the solver are discussed later in Sect. 5.

Figures 3 and 4 show the accuracy of PIFM-PS for $\theta=91$ $95^{\circ}$ as a function of altitude. At $326.5 \mathrm{~nm}$ the actinic flux decreases significantly between $20-60 \mathrm{~km}$ altitude due to the attenuation of the direct beam by Rayleigh scattering and ozone absorption. For this wavelength the actinic flux starts to decrease already at higher altitudes for higher incident angles, due to the longer path of the direct light through the atmosphere. At $610.0 \mathrm{~nm}$ the direct beam is much less attenuated, which results in a less marked decrease in the $F_{\text {act }}$ with respect to altitude. For this wavelength the $F_{\text {act }}$ decreases to very small values in the shadow of the Earth body, where only the diffuse component of the radiation is present. The PIFM_PS solver can reproduce this feature very well and overall the corresponding errors are small. Only at altitudes where the contribution of the direct beam to $F_{\text {act }}$ is negligible because of either the strong extinction which exists in the photon path or due to the shadow of the Earth body does the error increase to up to $\pm 30 \%$. However, due to the small values of $F_{\text {act }}$ at these altitudes this large error is of minor importance for our application. It should also be noted that an upper threshold of $\theta=93^{\circ}$ is used during the application of PIFM-PS following Lamago et al. (2003).

The subsequent error introduced into the final $J$ values as a result of using PIFM to calculate $F_{\text {act }}$ in Eq. (1) has been studied by Landgraf and Crutzen (1998) and is, on average, $\sim 5 \%$ for clear-sky conditions and $\sim 20 \%$ for cloudy 

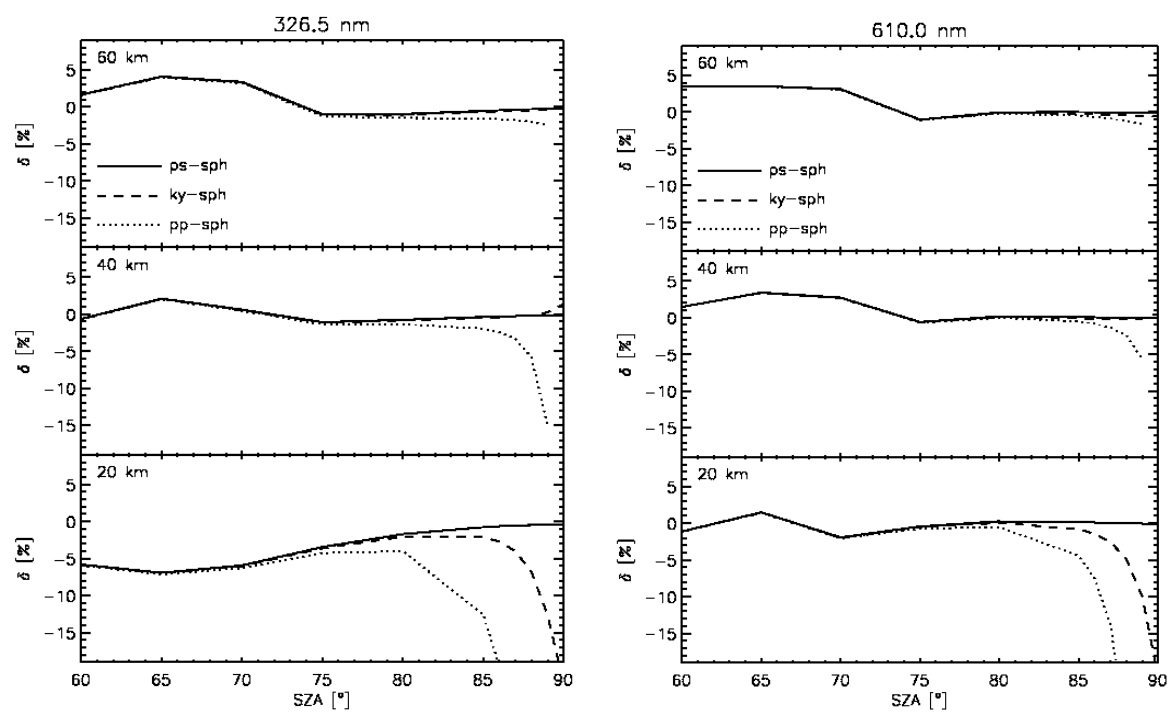

Fig. 2. Percentage differences $(\delta)$ in the actinic flux $\left(F_{\text {act }}\right)$ calculated with different model versions of PIFM versus a full spherical radiative transfer model as a function of the solar zenith angle (SZA). Differences in $F_{\text {act }}$ are shown for comparisons between the plane parallel PIFM version (pp), the version using the Kasten and Young correction for spherical air mass factors ( $k y)$ and the pseudo-spherical extension of PIFM (ps) versus reference model A (sph) at 20,40 and $60 \mathrm{~km}$ altitude. The left panel shows differences for $\lambda=326.5 \mathrm{~nm}$ and the right panel for $\lambda=610.0 \mathrm{~nm}$, which are pertinent to the scaling wavelengths chosen for grid A (see Table 1). The model atmosphere is adopted from the US standard atmosphere 1976 , albedo $=0 \%$ and the total ozone column scaled to $300 \mathrm{DU}$.
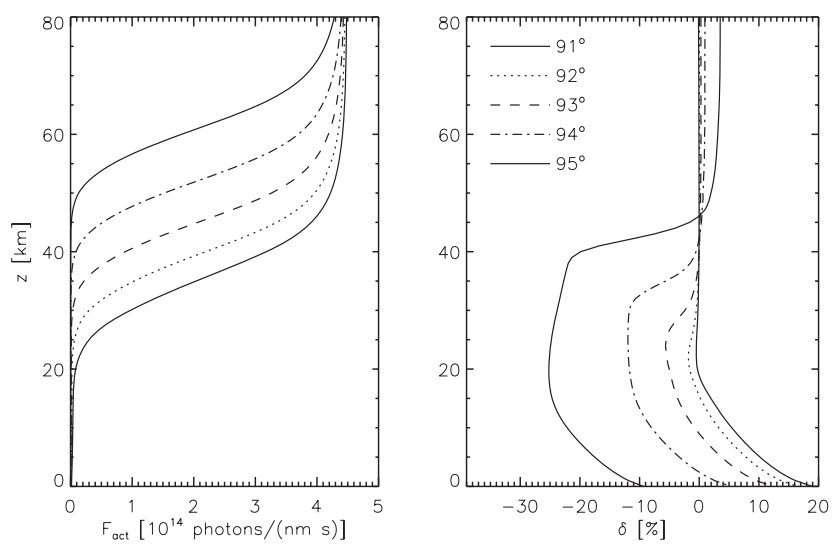

Fig. 3. The $F_{\text {act }}$ at $326.5 \mathrm{~nm}$ as a function of altitude for $\theta=91-95^{\circ}$ (left panel) and the associated error when comparing the PIFM-PS with reference model A (right panel). The model atmosphere is the same as in Fig. 2.

conditions for $\theta \leq 60^{\circ}$, as compared to the 32-stream discrete ordinate code of Stamnes et al. (1988). The maximum errors occur in the middle troposphere where the contributions due to multiple scattering are the greatest.

For the PIFM-PS solver the subsequent error introduced into the final $J$ values also needs to be quantified at high incident angles. Due the high computational effort involved in using reference A, the calculation of $J$ value profiles using full spherical geometry was not possible within a reasonable
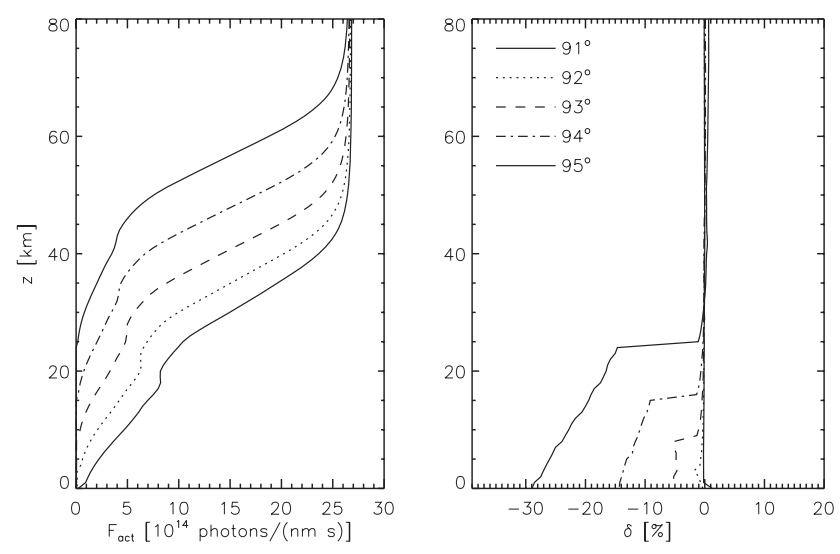

Fig. 4. Same as Fig. 3 but for $610.0 \mathrm{~nm}$.

time. Therefore, in order to quantify the error in the resulting $J$ values, we have interpolated the height resolved difference between actinic flux calculations performed using reference model A and PIFM-PS, which were calculated for the scaling wavelengths chosen for grid A (see Table 1), onto the working grid of Brühl and Crutzen (1988) for all 80 atmospheric layers. Subsequently we have scaled the PIFM-PS calculations on the working grid of Brühl and Crutzen (1988) with these error estimates to get a reliable estimate of the percentage error introduced into $F_{\text {act }}$. In turn we are able to estimate the corresponding errors in the $J$ value profiles at any particular zenith angle. 

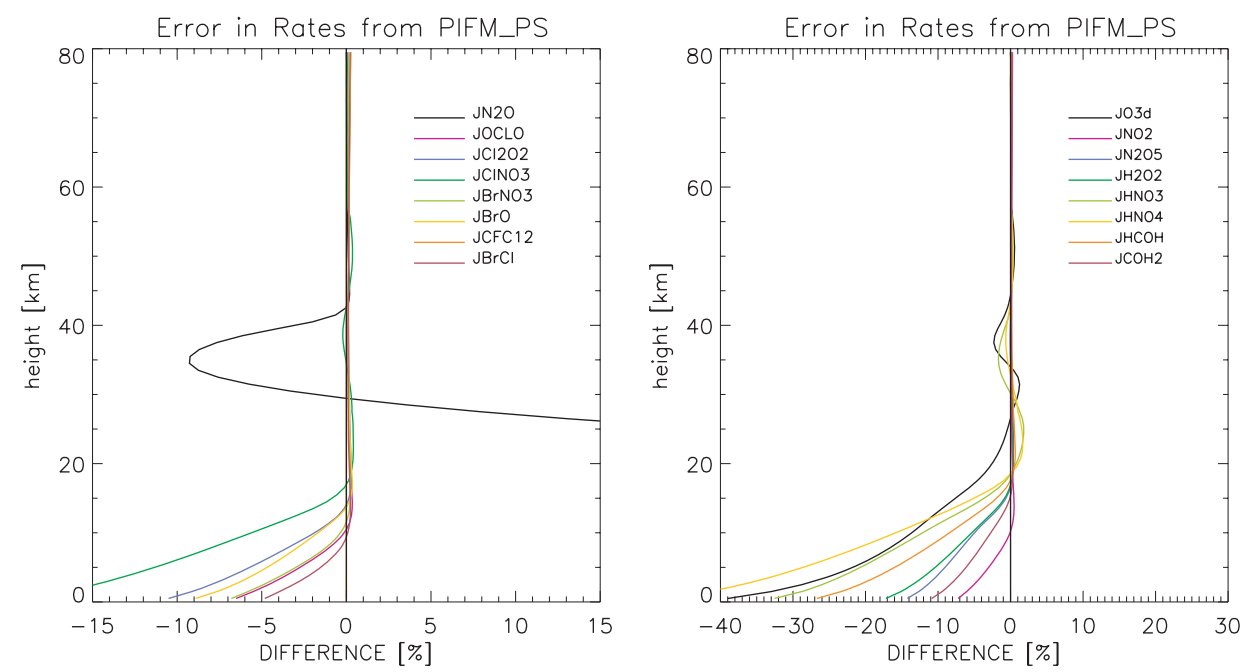

Fig. 5. Percentage errors associated with the $J$ value profiles calculated using the PIFM-PS model as compared with reference model A at $\theta=90^{\circ}$. For details regarding how the error was calculated the reader is referred to the text. Results are presented for (a) the stratospheric and (b) tropospheric chemical subsets, respectively. The model atmosphere is adopted from the US standard atmosphere 1976, albedo=0\% and the total ozone column scaled to $300 \mathrm{DU}$.

Figures 5a and b, show the associated errors due to PIFMPS at $\theta=90^{\circ}$ for both the stratospheric and tropospheric chemical subsets, respectively. These figures show that the errors for the first $40 \mathrm{~km}$ of the column are generally of the order of $\pm 2 \%$. Below this height the error increases substantially for species such as $\mathrm{N}_{2} \mathrm{O}$, although the actual $J$ value at this altitude is extremely small. For the other tropospheric species the errors down to $25 \mathrm{~km}$ are below $\pm 5 \%$, after which negative errors exist for all species. Fortuitously, the $J$ values become rather irrelevant at such high zenith angles in the lower portion of the column meaning that the effect on the overall performance of the PIFM-PS is minimal.

Figure 6 shows the corresponding errors for the worst case scenario of $\theta=93^{\circ}$. Again, the associated errors in the $J$ values for the top $40 \mathrm{~km}$ due to PIFM-PS were $\pm 2 \%$, except for $J_{\mathrm{N}_{2} \mathrm{O}}$. Below this height there is so little direct flux $\left(F_{\mathrm{abs}}\right)$ below $320 \mathrm{~nm}$ which penetrates through to the lower levels that the $F_{\text {act }}$ for this spectral region is determined almost purely by scattering. Therefore, the contributions by bands 1 to 4 subsequently decrease, resulting in lower errors in the $J$ values for the lowest $20 \mathrm{~km}$ of the column compared to $\theta=90^{\circ}$.

It should be noted that the effects of atmospheric refraction of the solar beam were not included in either reference model A or the PIFM-PS solver. To do so would involve a significant update to the reference code which is beyond the focus of this paper. Moreover, an iterative scheme would need to be introduced into the PIFM-PS solver for the derivation of a modified solar zenith angle for each respective level, which would significantly increase the computational burden of the solver. Although the effects on certain free radical species can be significant between $40-50 \mathrm{~km}$ when integrat- ing over a period of 7 days, the overall effect on $\mathrm{O}_{3}$ is thought to be relatively small (Balluch and Lary, 1997). Therefore, we feel that the error introduced into the calculation of height resolved $F_{\text {act }}$ is not dominant compared to the other uncertainties in (e.g.) the absorption characteristics for important chemical species such as $\mathrm{Cl}_{2} \mathrm{O}_{2}$ (Sander et al., 2003).

In summary, the modification to the two-stream approximation reduces the error introduced by using the two-stream approximation significantly, especially at the altitudes important during instances of very low sun $\left(\theta>90^{\circ}\right)$.

\subsection{The scaling ratios $\left(\delta_{i}\right)$}

The most important assumption made in the band approach is that the $F_{\text {act }}$ scales with its direct component $\left(F_{\mathrm{abs}}\right)$ within a specific wavelength band at any altitude, where the scaling ratio is assumed to be wavelength independent within a spectral band. This assumption has enhanced importance when the amount of incident radiation varies strongly within a spectral band (e.g. band 4). For such instances the approach only holds for situations where the diffuse radiation is governed by the direct component due to the single scattering contribution of solar light at the same altitude. In instances where the diffuse component is scattered from other parts of the atmosphere this approximation breaks down. Such conditions are encountered for low sun at wavelengths which exhibit strong to moderate $\mathrm{O}_{3}$ absorption $(<305 \mathrm{~nm})$, resulting in a direct flux in the lower atmosphere which is very small. For such a case the diffuse radiation mainly originates from scattering which occurs at higher altitude levels. Thus it would be more appropriate to use the scaling ratio calculated at higher altitudes for the lower levels. However, for the 

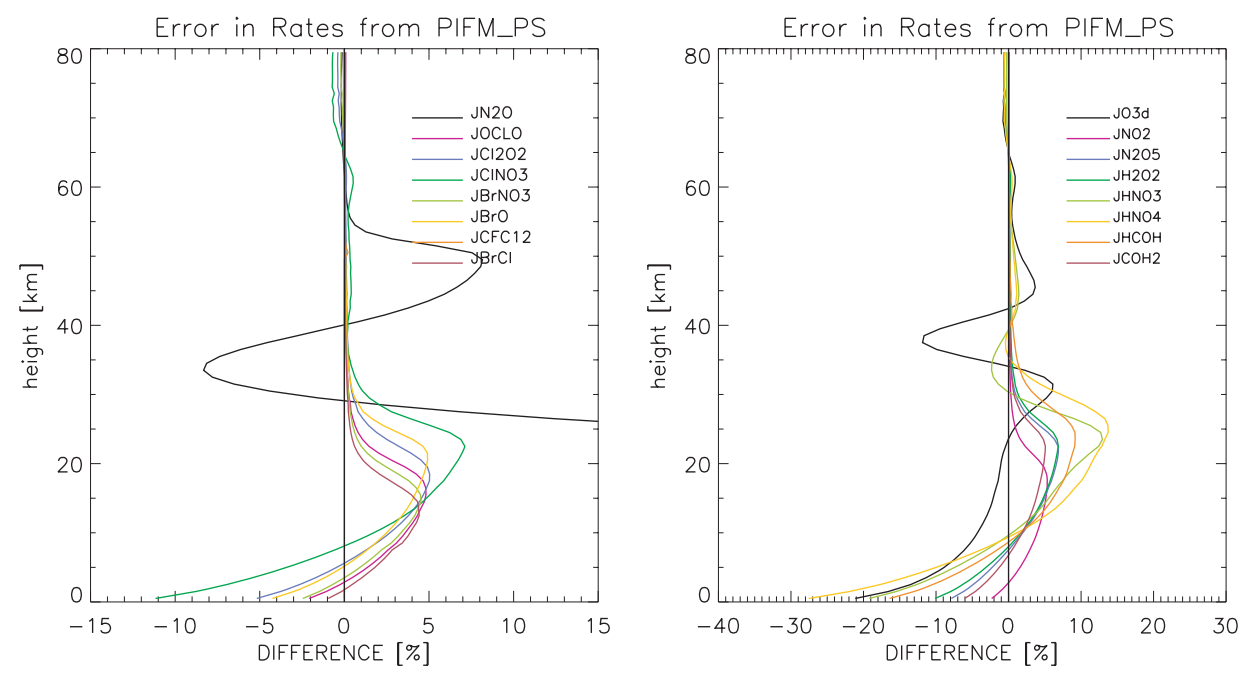

Fig. 6. As for Fig. 5 except the $\theta=93^{\circ}$.

Table 4. The flux thresholds adopted for $F_{\text {abs }}$ during the calculation of the scaling ratios for bands 2 through to 4 at $\theta>81^{\circ}$. The ratio for $F_{\mathrm{abs}} / F_{0}$ is given using photons $\mathrm{nm}^{-1} \mathrm{~s}^{-1}$ for the original fluxes. These ratios hold for the scaling wavelengths given in Table 1.

\begin{tabular}{cll}
\hline Band & $\theta: 81-85^{\circ}$ & $\theta:>85^{\circ}$ \\
\hline 2 & $1.2 \times 10^{-4}$ & $1.2 \times 10^{-4}$ \\
3 & No limit & $4.5 \times 10^{-12}$ \\
4 & $2.7 \times 10^{-5}$ & $1.35 \times 10^{-6}$ \\
\hline
\end{tabular}

numerical implementation we apply a limit on the resulting scaling ratios whenever $F_{\text {abs }}$ falls below a selected threshold value, which effectively means using a $\delta_{i}$ value calculated for higher altitudes. The diagnostic used for the derivation of these $F_{\text {abs }}$ thresholds was the occurrence of large associated errors on the most sensitive $J$ values accompanied by correspondingly high $\delta_{i}$ values. In general, it was found that $\delta_{i}$ values greater than 10 resulted in an overestimation of the resulting band contribution to the final $J$ values. For species which exhibit strong absorption characteristics for $\lambda<320 \mathrm{~nm}\left(\right.$ e.g. $\mathrm{O}_{3}, \mathrm{HNO}_{3}$ ) it was found that such limits are needed for $\theta>81^{\circ}$ in order to reduce the associated error budgets. These were applied to bands 2 and 4 for the species highlighted in red in Table 2. Once the $\theta>85^{\circ}$ such limits were applied for band intervals 2 through to 4 for all chemical species, using the $\left(F_{\mathrm{abs}} / F_{o}\right)$ ratios given in Table 4 . It should be noted that the ratios for these limits change for certain bands for incident angles above and below $\theta=85^{\circ}$ as a consequence of using PIFM-PS at $\theta>85^{\circ}$, which modifies the $F_{\text {abs }}$ component. No limits were applied to bands 1 or 5 through to 8 under any circumstances. For bands 6 through to
8 a sufficient amount of direct light penetrates through to the lower layers so as to ensure that the main assumption used in the band model never fails, even at high zenith angles.

A further modification to the band approach is the introduction of a scaling ratio for the first band. An assumption is made in the original band approach that absorption dominates for $\lambda \leq 202 \mathrm{~nm}$. This assumption only holds when the single scattering contribution to $F_{\text {act }}$ can be neglected compared to $F_{\text {abs }}$. Here the single scattering contribution from a certain model layer scales with the transmission of the atmosphere located above that layer and the amount of radiation deposed in the model layer. Furthermore, the single scattering contribution is proportional to the single scattering albedo. However, this term does not depend on solar geometry. For $\theta<70^{\circ}$ the single scattering contribution is insignificant because the fraction of radiation deposed in the specific model layer is small and, in combination with the low single scattering albedo higher up in the atmosphere, results in the scattering of light being relatively unimportant. For lower sun, the path length of the solar beam through a model layer increases markedly which enhances the fraction of radiation deposed in each atmospheric layer. Figure 7 highlights this by showing the relative distance over which a photon must travel (the slant path) to an atmospheric layer which has been chosen in the model atmosphere for two different incident zenith angles. Therefore, for large slant paths, the scattering contribution becomes a significant part of the total flux in the upper part of the atmosphere. For this reason, it is necessary to use a scaling ratio for $\theta>72^{\circ}$ for the first spectral band which accounts for this behaviour. 


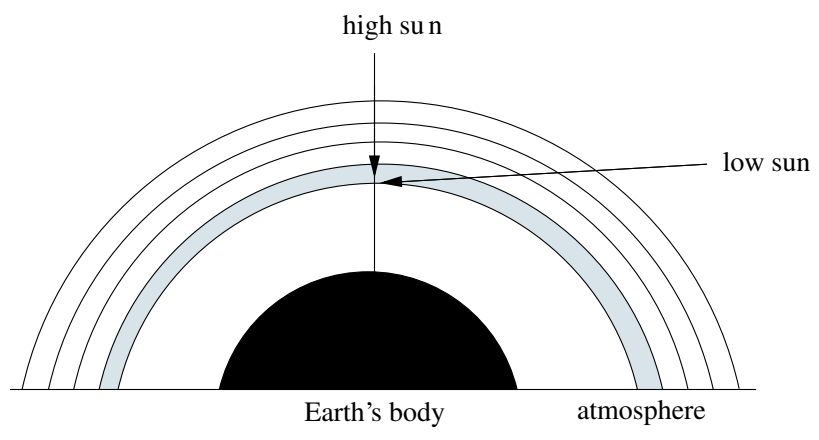

Fig. 7. The variation in the slant path over which a photon has to travel to reach a particular layer (highlighted in grey) in the model atmosphere. For high sun a large amount of radiation can reach the top of this model layer. However, due to the relatively short pathlength of the solar beam through the layer, there is no significant contribution of singly scattered light in this model layer. For low sun the amount of direct light illuminating the top of the highlighted layer is less as a consequence of the longer light path. However it can be still sufficient to cause a significant contribution of singly scattered light in the model layer below in conjunction with the relatively large pathlength through the grey model layer for this geometry.

\subsection{Selection of the band limits}

Due to the shift of the amount of radiation towards longer wavelengths in instances of low sun, the band settings of Landgraf and Crutzen (1998) have to be modified for the band approach to maintain optimal performance at high incident zenith angles. Figure 8 shows the relative actinic flux $t(\lambda)=F_{\text {act }}(\lambda) / F_{o}(\lambda)$ at $10 \mathrm{~km}$ altitude between $300-320 \mathrm{~nm}$, normalized to the corresponding value at $310 \mathrm{~nm}$, across a range of solar zenith angles. Here the actinic flux below $310 \mathrm{~nm}$ decreases relative to the centre wavelength with respect to solar zenith angle, whilst increases occur for wavelengths above $310 \mathrm{~nm}$. In other words, the relative amount of radiation is shifted towards longer wavelengths for larger solar zenith angles due to the longer path length of the direct beam through the atmosphere. This effect holds at this particular altitude until a $\theta=80^{\circ}$, after which the shift in radiation towards longer wavelengths becomes weaker. This can be explained by the presence of the stratospheric ozone layer in combination with the spherical shape of the atmosphere. This behaviour is not seen for layers above the ozone layer or when adopting the plane parallel approximation of the model. In turn, the band limits and $\delta_{i}$ values of the band model become non-optimal, which subsequently results in errors of between 10-30\% which generally occur in the lowest $10 \mathrm{~km}$ of the atmosphere for important tropospheric species (e.g. $J_{\mathrm{H}_{2} \mathrm{O}_{2}}$ ) when the $\theta>80^{\circ}$.

An optimalization of the band settings for low sun is limited by the requirements that the scheme should calculate height resolved $J$ values for a diverse range of species over

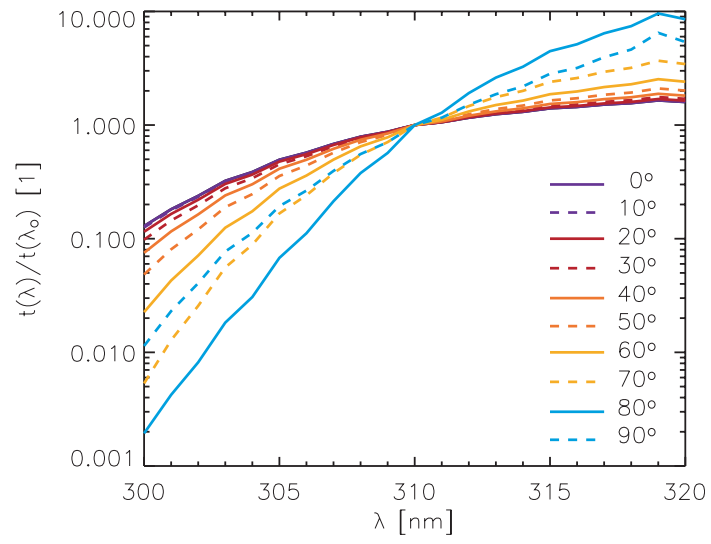

Fig. 8. Relative actinic flux $t(\lambda)=F_{\text {act }}(\lambda) / F_{o}(\lambda)$ between 300 $320 \mathrm{~nm}$, normalized to the corresponding value at $310 \mathrm{~nm}$, as a function of solar zenith angle at $10 \mathrm{~km}$ altitude. For details regarding the model atmosphere the reader is referred to Sect. 3.1. Calculations were performed using the original band settings in conjunction with the original input parameters for the temperature dependent $\sigma$ and $\phi$ of $\mathrm{O}_{3}$. The total ozone column was scaled to $300 \mathrm{DU}$ and the ground albedo $=5 \%$.

the entire model atmosphere. Moreover, the percentage contribution by each band to each $J$ value is also dependent on height for many chemical species. Figure 9 shows an example of this effect, where the variation in the percentage contributions made by each spectral band to $J_{\mathrm{O}_{3}}\left(\rightarrow \mathrm{O}^{1} \mathrm{D}\right)$ and $J_{\mathrm{BrNO}_{3}}$ is shown with respect to the zenith angle, for clear sky conditions at two model layers situated at 65 and $5 \mathrm{~km}$. These contributions are derived using the original band settings as given in Table 1 . For the layer at $65 \mathrm{~km}$ it can be seen that $J_{\mathrm{O}_{3}}\left(\rightarrow \mathrm{O}^{1} \mathrm{D}\right)$ is principally determined by contributions originating from band 3 , which contains the absorption maximum for $\mathrm{O}_{3}$. In contrast, due to the overhead $\mathrm{O}_{3}$ column being relatively low at this altitude and the broad absorption characteristics of $\mathrm{BrNO}_{3}$, contributions are made to $\mathrm{JrNO}_{3}$ across the entire spectral range i.e. bands 1 to 8 . Moreover, the contribution made by each band to $\mathrm{JrNO}_{3}$ only changes marginally as the zenith angle increases until $\theta \approx 90^{\circ}$. However, nearer the ground the percentage contributions made by each band change considerably as a consequence of the effective screening of the far UV by molecular $\mathrm{O}_{2}$ and $\mathrm{O}_{3}$. This screening results in the contributions made by bands 1 through to 3 to be extremely small in the lower layers, resulting in a decrease in the $J$ values with respect to height. As the value of $J_{\mathrm{O}_{3}}\left(\rightarrow \mathrm{O}^{1} \mathrm{D}\right)$ in the lower layers decreases with increasing zenith angle (not shown), the percentage contribution made by band 4 also decreases (with an associated increase in the percentage contribution made by band 6) until $\theta=80^{\circ}$. For $\theta>80^{\circ}$ the contribution made by band 4 at this particular altitude starts to increase again due to the sphericity of the Earth's atmosphere. At these geometries the path length of the direct beam through the ozone layer decreases 

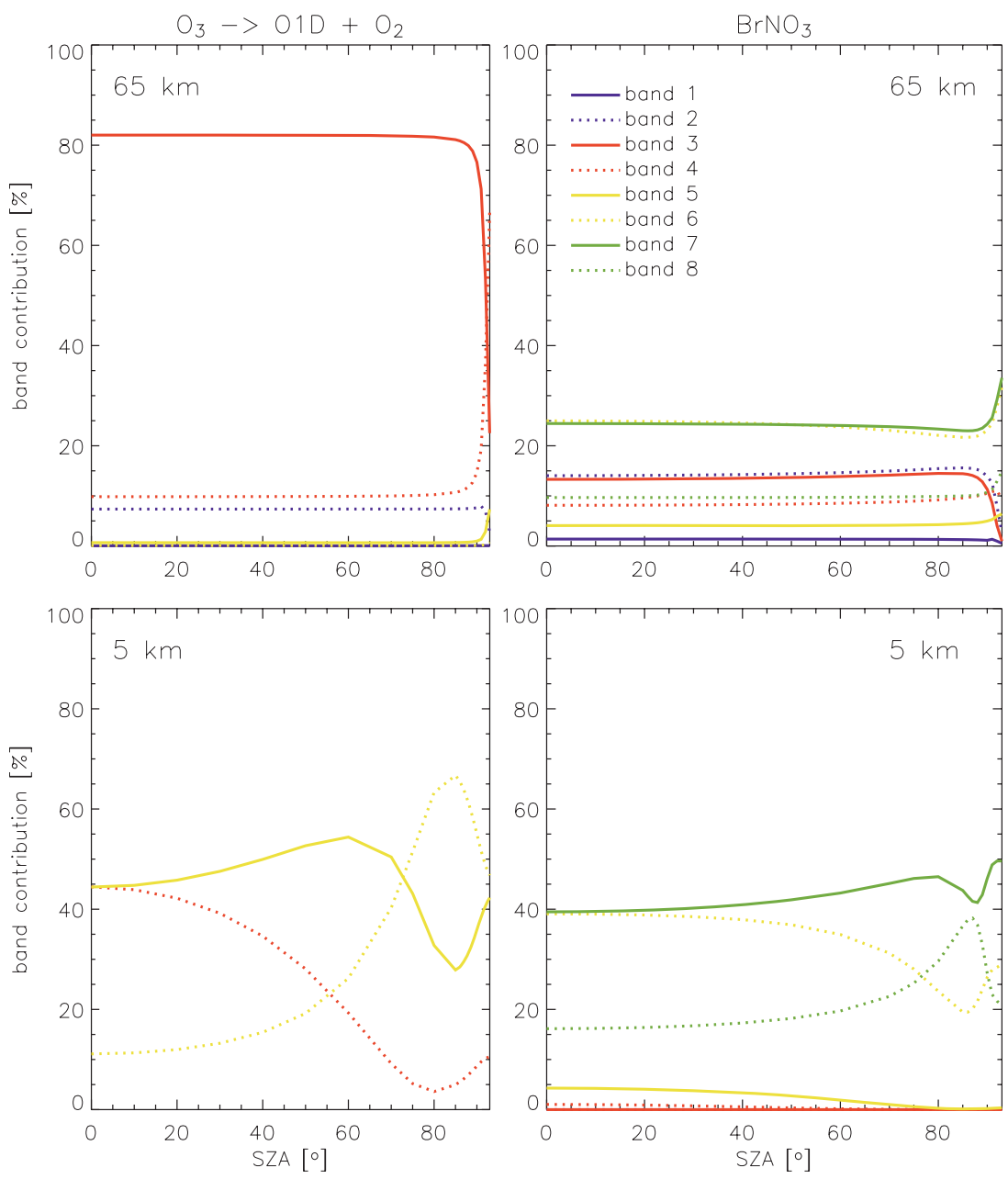

Fig. 9. The percentage contributions made by each spectral band for the calculation of $J_{\mathrm{O}_{3}} \rightarrow \mathrm{O}^{1} \mathrm{D}$ and $J_{\mathrm{BrNO}_{3}}$ at 5 and $65 \mathrm{~km}$ using the band method. These contributions were determined using the original band settings taken from Landgraf and Crutzen (1998). The total ozone column was scaled to $300 \mathrm{DU}$ and a ground albedo $=5 \%$.

with an increasing solar zenith angle. In turn, the relative amount of radiation is shifted towards shorter wavelengths, which increases the contributions made by bands 4 and 5 . As a result, there is a corresponding decrease in the percentage contribution made by band 6 to $J_{\mathrm{O}_{3}}\left(\rightarrow \mathrm{O}^{1} \mathrm{D}\right)$. The actual percentage contributions are weighted by the absorption characteristics of molecular $\mathrm{O}_{3}$. For $J_{\mathrm{BrNO}_{3}}$ a similar effect is observed near ground level, where the contributions from bands 1 through to 5 are screened out meaning that $J_{\mathrm{BrNO}_{3}}$ is principally determined by the contributions from bands 6 through to 8 . The optimialization of the band limits is hampered by such height dependent contributions from different bands, meaning that large associated errors maybe easily introduced into the $J$ values in either the stratosphere or troposphere if one does not assess the error throughout the entire column.

For the determination of the band parameters for $\theta>72^{\circ}$ various combinations of $\lambda(i)_{\min }, \lambda(i)$ and $\lambda(i)_{\max }$ were tested and the resulting errors in the $J$ values assessed to discern whether any significant reduction in errors occurred compared to the original band settings. A limitation was found to exist in the choice of band limits for band 4 due to many of the species in the tropospheric subset exhibiting strong absorption in the spectral range covered by this band. Therefore, the resulting errors for such species were very sensitive to where the limits for this band were placed on the spectral grid. For bands 5 to 8 it was found that the accuracy of the method was increased by shifting the band limits and $\lambda(i)$ towards the visible end of the spectrum, although $\lambda(8)_{\max }$ remained unchanged. This procedure was performed for the zenith angle ranges $\theta=72-85^{\circ}$ and $\theta=85-93^{\circ}$, resulting in parameter grids $\mathrm{A}$ and $\mathrm{B}$, respectively (see Table 1). A criterion used for the selection of the optimal band settings was that the errors introduced by the band approach should not be greater than $\pm 10 \%$ for the majority of the chemical species. Additionally, the errors should decrease compared 
to those obtained using the original band settings for almost all of the chemical species. These grids were used for the calculation of all $J$ values listed in Table 3, with the exception of $J_{\mathrm{NO}}$, for the specified ranges of $\theta$. For $\mathrm{J}_{N O}$ contributions are only made for a few of the wavelength bins in band interval 1 (Allen and Frederick, 1982) which were summed explicitly outside of the band limits

\section{Assessment of the performance of the modified band approach}

In this section we assess the performance of the band approach using the optimalized band settings (grid A and B in Table 1) and compare the resulting errors with those calculated using the original band settings. A range of atmospheric conditions have been chosen which are thought to cover the most important cases found in a CTM. The chemical subsets defined in Table 3 are used for this purpose. Moreover, for further brevity we limit the discussion below to the errors introduced when using a "final working version" of the modified band approach. This "final working version" was the result of several upgrades made to the fully explicit code driven by the need to remove the most computationally expensive interpolation steps. Therefore, a look-up table for the temperature dependent absorption parameters (namely $\sigma$ and $\phi$ values) was produced using a resolution of $5^{\circ} \mathrm{C}$ over the temperature range $180-340^{\circ} \mathrm{C}$ and indexed using the temperature of each atmospheric layer. Various look-up tables with differing resolutions between $1-10^{\circ} \mathrm{C}$ were tested (not shown) and the $5^{\circ} \mathrm{C}$ resolution found to be both accurate and concise. Comparisons are made versus a version of the model which calculates $F_{\text {act }}$ explicitly for each wavelength bin of the working spectral grid of Brühl and Crutzen (1988), without the use of a look-up table for the temperature dependent absorption parameters (hereafter referred to as reference B). It should be noted that both the "final working version" and reference B both use either PIFM-KY or PIFM-PS to calculate $F_{\text {act }}$ values for ranges of $\theta$ above and below $\theta=85^{\circ}$, respectively. As a result, the following comparison pertains to the cumulative error introduced by both the modified band method and by the use of offline look-up tables for the $\sigma$ and $\phi$ parameters.

\subsection{Clear-sky and aerosol free conditions}

\subsubsection{Errors for $\theta=72-85^{\circ}$}

In this section we investigate the performance of the modified band approach under clear sky conditions over the range of $\theta=72-85^{\circ}$ using grid $\mathrm{A}$ and present errors for certain species chosen from both the stratospheric and tropospheric subsets of chemical species.

Figures $10 \mathrm{a}$ and $\mathrm{d}$ show the typical variation in $J$ values, with respect to height, for both the stratospheric and tropospheric chemical subsets, respectively, under clear sky condi- tions at $\theta=80^{\circ}$ and assuming an albedo of $5 \%$. These profiles were calculated using the "final working version" of the photolysis scheme in conjunction with the original band settings (cf. Table 1). Figures 10b and e show the resulting errors as for the stratospheric and tropospheric chemical subsets compared with reference model B, respectively. The saw-tooth feature, which is evident in the error diagrams for certain species, is due to the use of the look-up table for the temperature dependent $\sigma$ values (cf. the smooth error profiles which exist for species that have no temperature dependencies). The corresponding errors when using grid A are shown in Figs. 10c and f, respectively. By comparing the appropriate figures it can be seen that the application of grid A leads to substantially lower errors for both chemical subsets, especially for $\mathrm{BrO}, \mathrm{CFC} 12, \mathrm{HCHO}$ and $\mathrm{H}_{2} \mathrm{O}_{2}$, where the error is approximately halved. It should be noted that the increase in the associated error for both $J_{\mathrm{N}_{2} \mathrm{O}}$ and $J_{\mathrm{CFC} 12}$ below $40 \mathrm{~km}$ relates to $J$ values that are very small which tends to amplify the error introduced by small differences.

Figures $11 \mathrm{a}-\mathrm{h}$ show the resulting contour plots for the variation in the error budgets with respect to incident zenith angle when using both the original and modified band approaches. The corresponding contour plots for the tropospheric chemical subsets are shown in Figs. 12a-p, respectively. To aid comparison the results obtained using both band settings are placed side-by-side. By comparing these figures it can be seen that there are substantial reductions in the errors obtained using the modified version of the band approach for both of the chemical subsets. For the stratospheric subset only a small selection of the chemical species are shown, with the other species having associated errors of $\pm 3 \%$ for both the original and modified version of the approach (although a reduction in error is always observed using grid A). For those included in Fig. 11 all errors are below $10 \%$ for the first $50 \mathrm{~km}$ of the column across the entire range of incident $\theta$, with the exception of $J_{\mathrm{CFC} 12}$. For this case the error drops substantially in the middle atmosphere due the use of the scaling ratio for band 1 (the band limits are identical for band1 between the original grid and grid A - see Table 1). It is also interesting to note that for the original band settings as the incident zenith angle increases some chemical species exhibit a reduction in the associated error as the contributions by each band to the total $J$ value change (e.g. $J_{\mathrm{BrO}}$, Fig. 11e).

For the tropospheric subset the resulting errors are larger for the bottom $25 \mathrm{~km}$ of the column, especially for the original band settings. The zenith angle at which the associated errors show a significant increase is $\theta=82^{\circ}$, with the exception of $J_{\mathrm{NO}_{2}}$ (Fig. 12c). This is due to an over-estimation of the band contribution made by band 4 to the final $J$ value when using the original method, as a consequence of a large $\delta_{i}$ value (i.e. low $F_{\text {abs }}$, see Sect. 3.3 ) in conjunction with the use of non-optimal band parameters. The most dramatic reduction in the associated errors occurs due to the application of limits on the $\delta_{i}$ values as can be seen for $\mathrm{O}_{3}$ when 

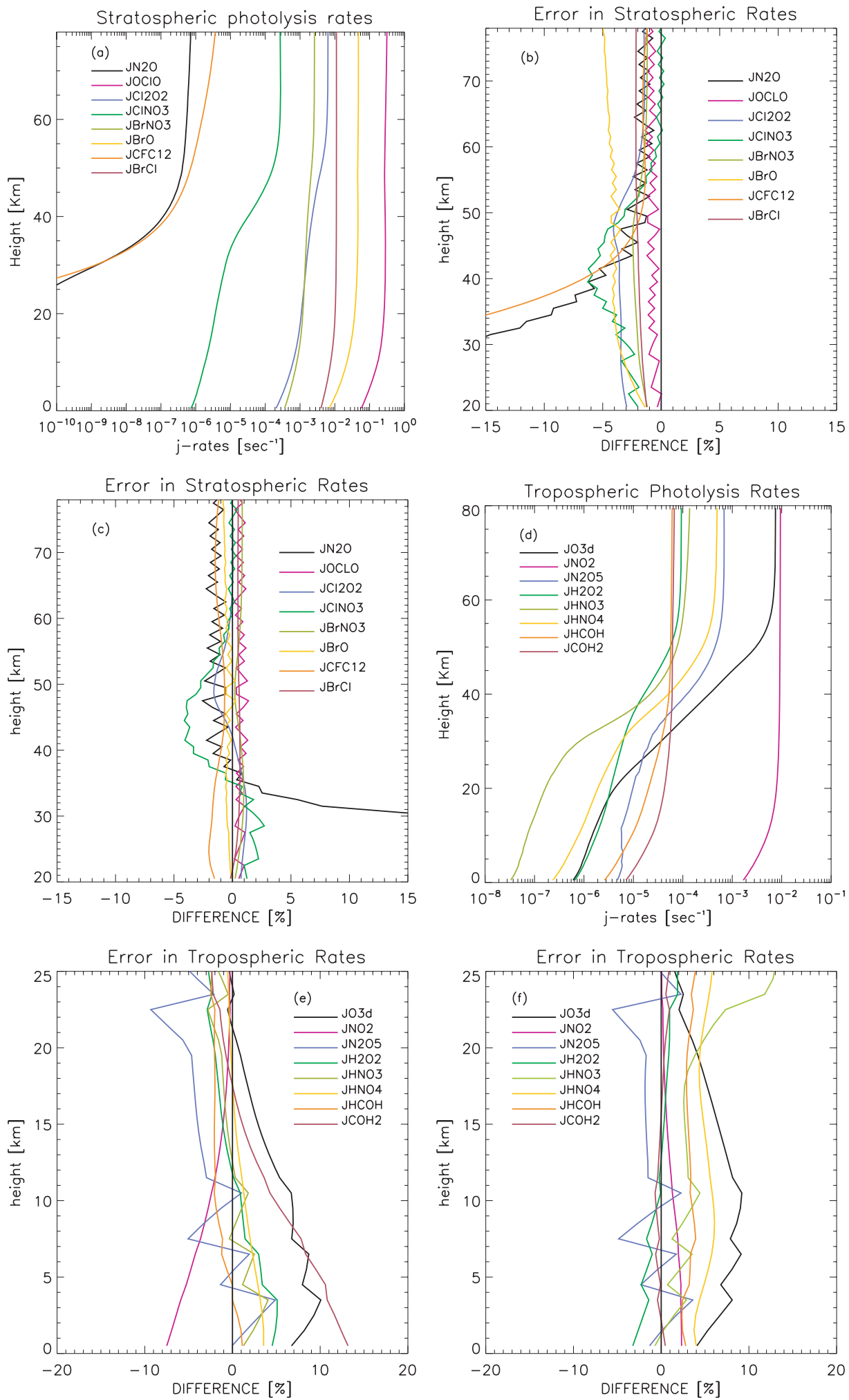

Fig. 10. Typical $J$ value profiles calculated for (a) the stratospheric and (d) the tropospheric subsets of chemical species at $\theta=80^{\circ}$ using a ground albedo $=5 \%$. The associated errors introduced by using the "final working version" of the code are also shown for the stratospheric subset when adopting (b) the original band settings as taken from Landgraf and Crutzen (1998) and (c) Grid A. All comparisons are made against reference model B. Plates (e) and (f) show the corresponding information for the tropospheric subset. 

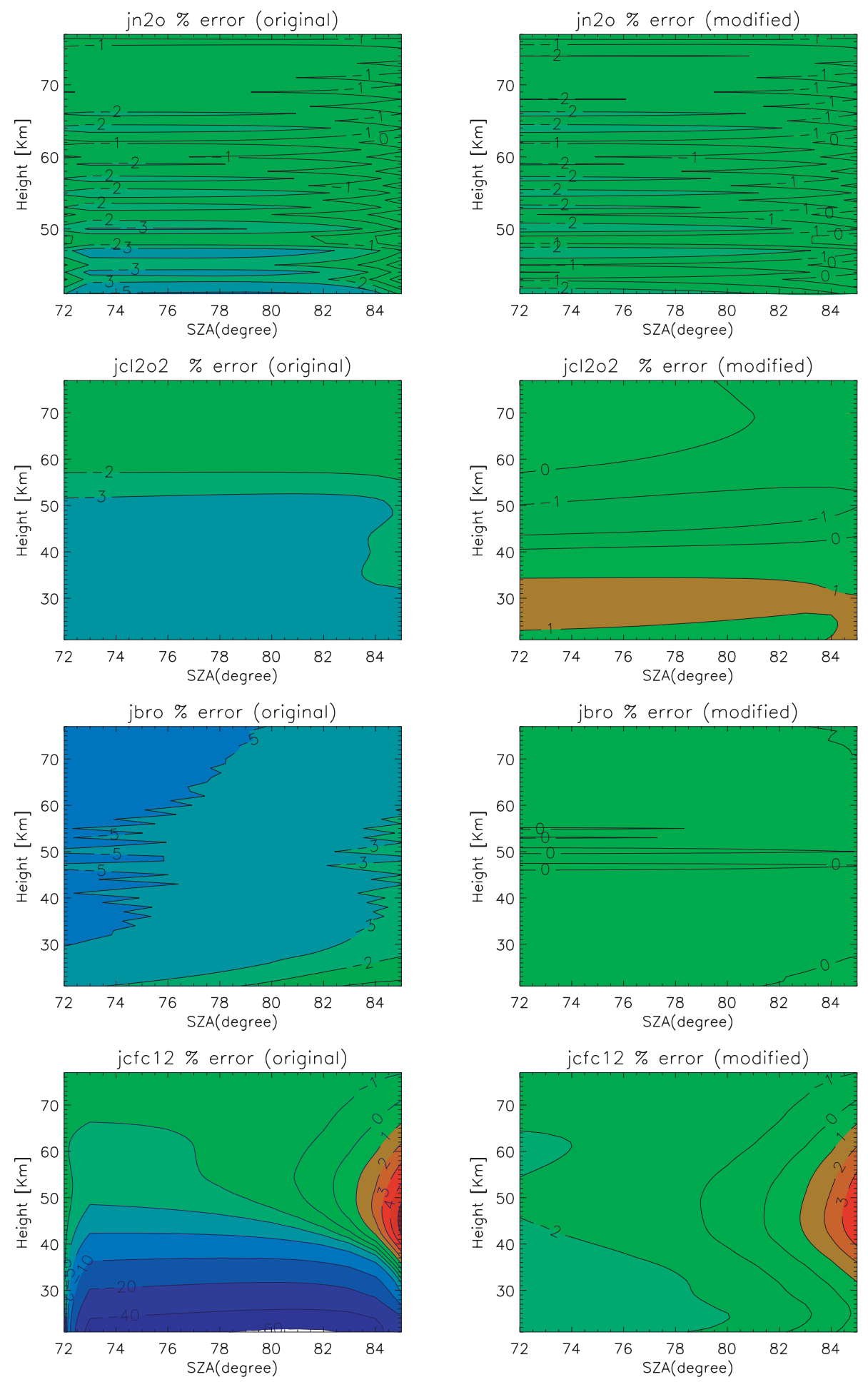

Fig. 11. The variation in the error budgets associated with the $J$ values calculated using both the original and modified band approaches for (a) $\mathrm{N}_{2} \mathrm{O}$, (b) $\mathrm{Cl}_{2} \mathrm{O}_{2}$, (c) $\mathrm{BrO}$ and (d) $\mathrm{CFC} 12$, with respect to the incident $\theta$. Comparisons are made against reference $\mathrm{B}$. Plots are shown for a clear-sky scenario, where the total ozone column was scaled to $300 \mathrm{DU}$ and a ground albedo $=5 \%$ adopted.

comparing Figs. 12a and $\mathrm{b}$ (i.e. the reduction in error due to the use of grid A alone is limited to $\pm 10 \%$ ). Although some error is still introduced by applying such limits (be- tween $\pm 10-20 \%$ for the lowest $10 \mathrm{~km}$, see Fig. 12b) the maximum error drops by an order of magnitude. A similar reduction in the error budgets is also observed for $\mathrm{HNO}_{3}$ 

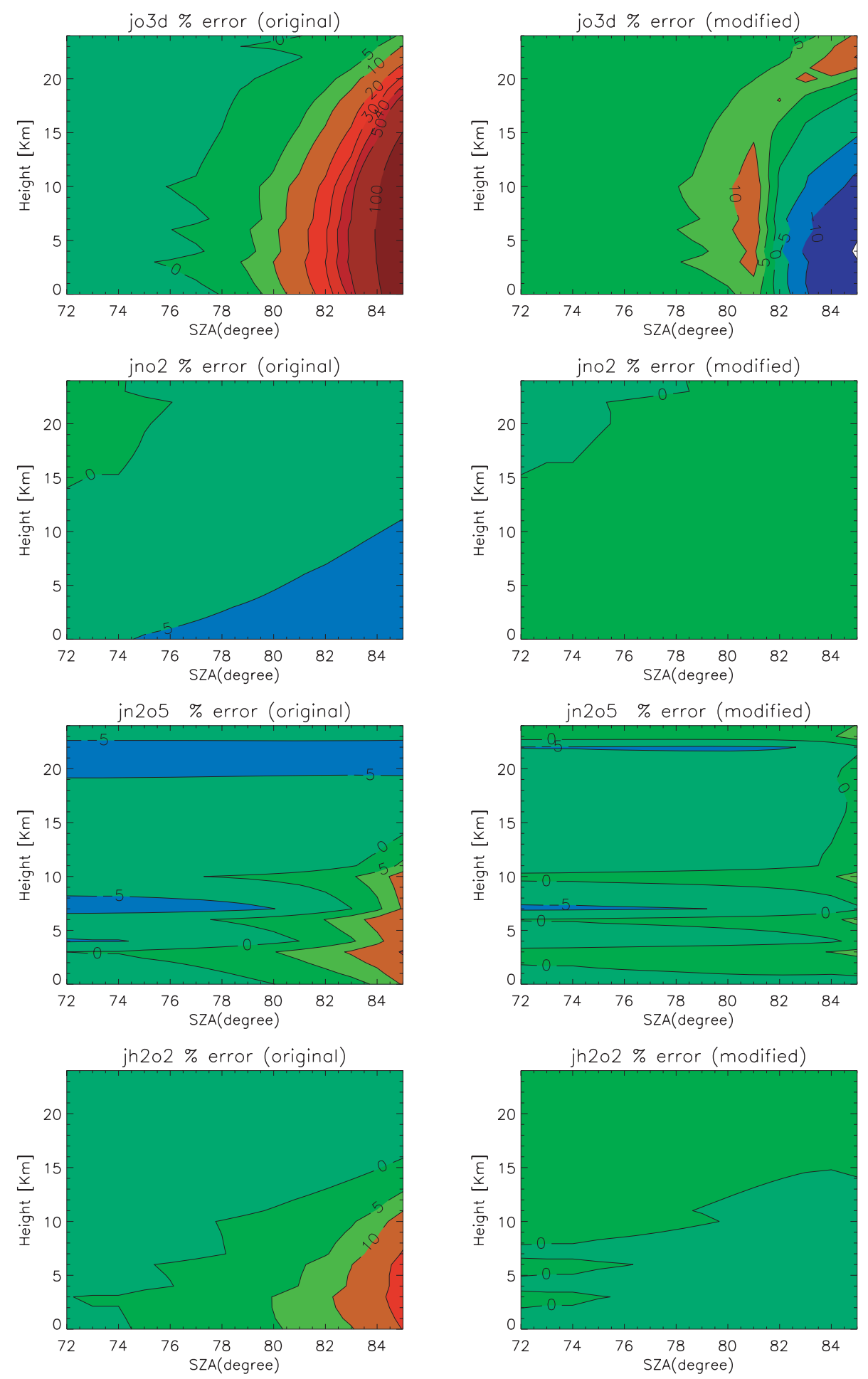

Fig. 12. The variation in the error budgets associated with the $J$ values calculated using both the original and modified band approaches for (a) $\mathrm{O}_{3} \rightarrow \mathrm{O}^{1} \mathrm{D}$, (b) $\mathrm{NO}_{2}$, (c) $\mathrm{N}_{2} \mathrm{O}_{5}$ and (d) $\mathrm{H}_{2} \mathrm{O}_{2}$, with respect to the incident $\theta$. Comparisons are made against reference $\mathrm{B}$. Conditions are identical to those described for Fig 11.

and $\mathrm{HNO}_{4}$. However, the application of the limits across all species results in a decrease in the accuracy of the modified band method for species such as $\mathrm{H}_{2} \mathrm{O}_{2}$ due to the characteristic absorption properties exhibited within particular bands 

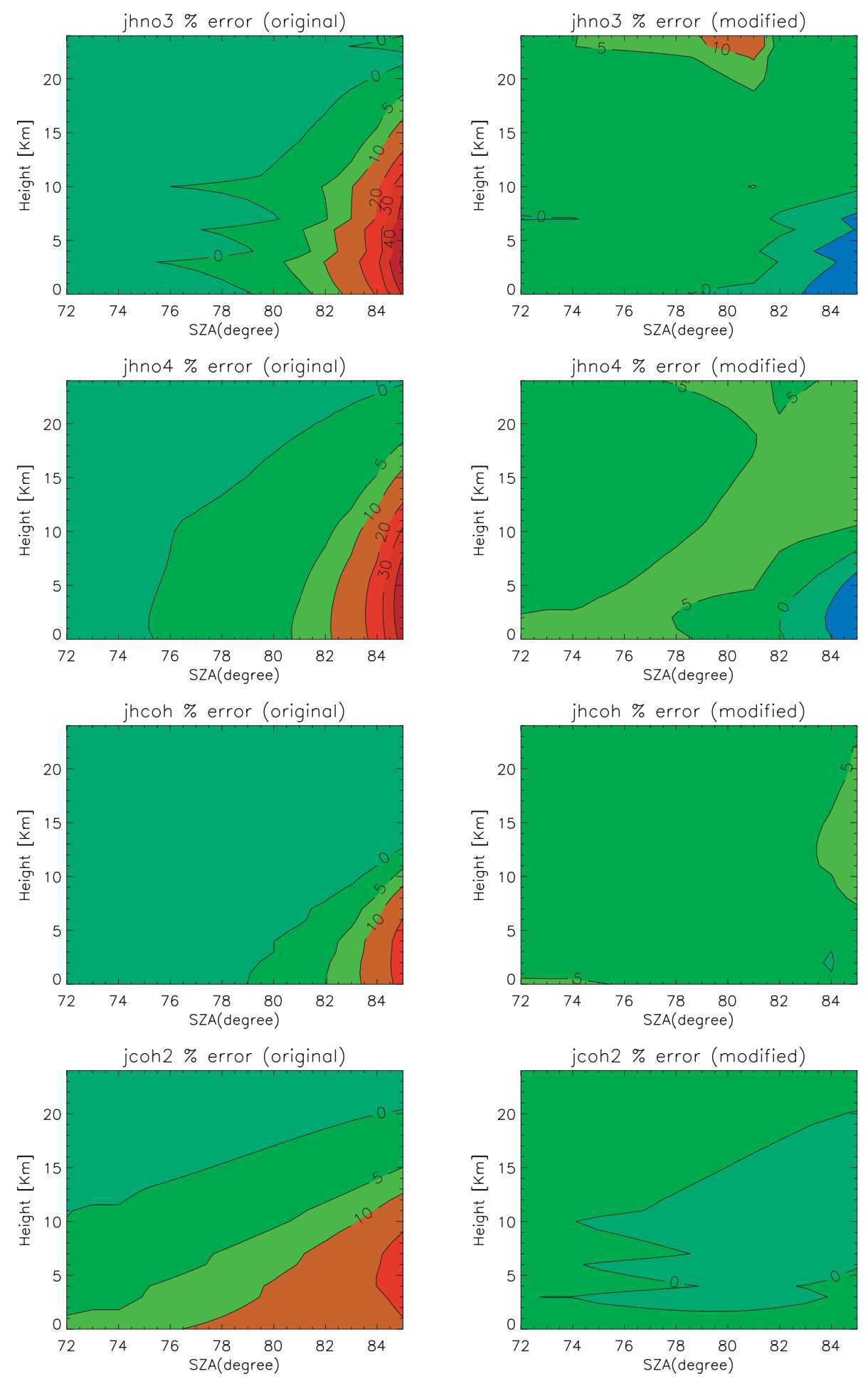

Fig. 12. Continued. The variation in the errors associated with the $J$ values calculated using both the original and modified band approaches for (a) $\mathrm{HNO}_{3}$, (b) $\mathrm{HNO}_{4}$, (c) $\mathrm{HCHO} \rightarrow \mathrm{HCO}+\mathrm{H}$ and (d) $\mathrm{HCHO} \rightarrow \mathrm{CO}+\mathrm{H}_{2}$, with respect to the incident $\theta$. Comparisons are made against reference B. Conditions are identical to those described for Fig. 11.

(not shown). Therefore, for $\theta \leq 85^{\circ}$, the use of such limits should be selective and tests made for each particular species included within the photolysis scheme. The species for which a significant reduction in errors is observed due to the application of such limits are highlighted in red in the comprehensive list of photolysis reactions given in Table 2 . 

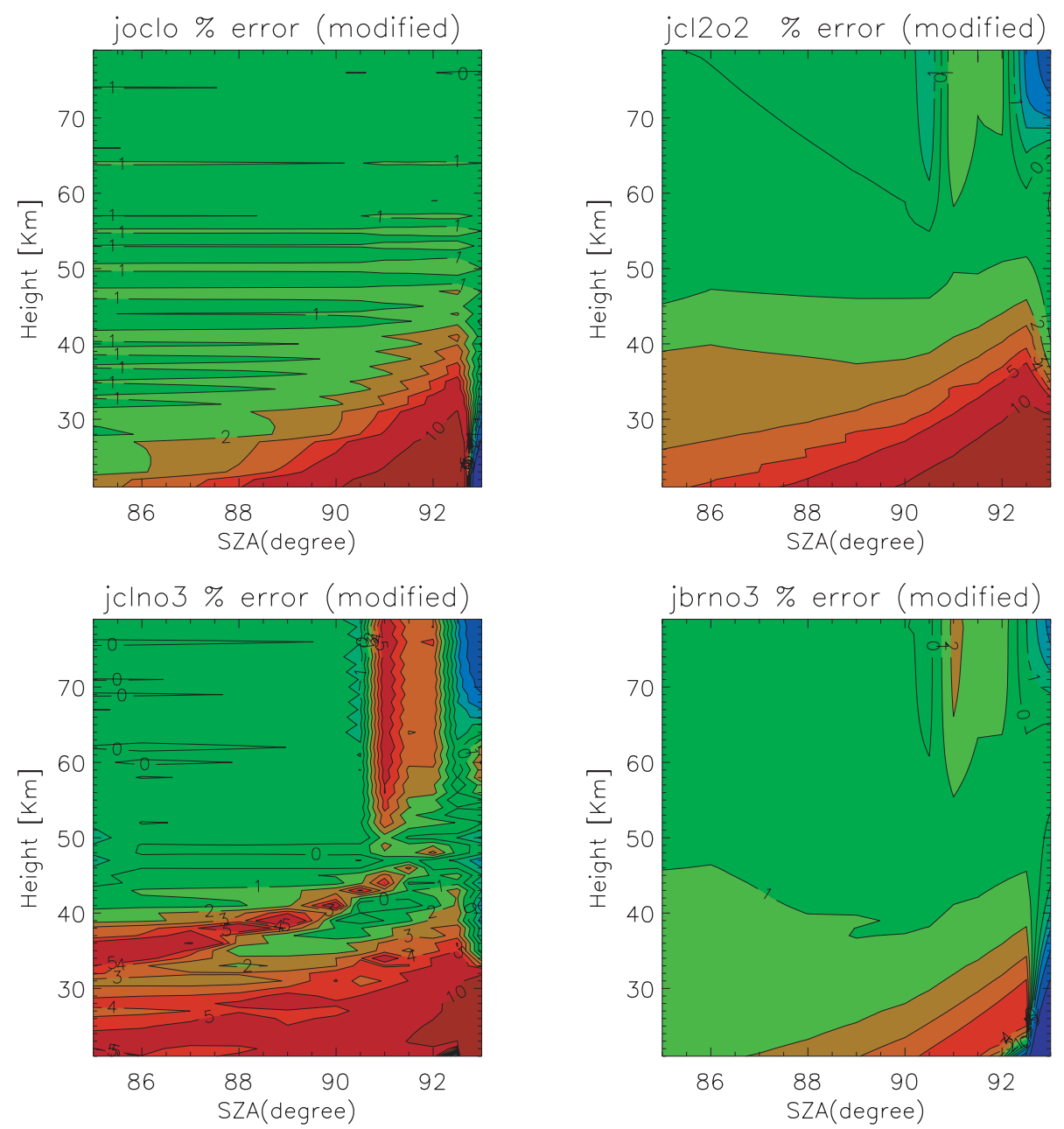

Fig. 13. The variation in the errors budgets associated with $J$ values for (a) $\mathrm{OClO},(\mathbf{b}) \mathrm{Cl}_{2} \mathrm{O}_{2}$, (c) $\mathrm{ClNO}_{3}$, and (d) $\mathrm{BrNO}_{3}$ with respect to incident $\theta$ for a clear-sky scenario using grid B. Comparisons are made against reference B. Results are shown for the range $\theta=85-93^{\circ}$ using the PIFM-PS solver. Conditions are identical to those described for Fig. 11.

The sensitivity of the band method to the values of $\sigma$ and $\phi$ can be elucidated by comparing Fig. 12a with Fig. 5 in Landgraf and Crutzen (1998). Here, the associated errors calculated for $J_{\mathrm{O}_{3}}\left(\rightarrow \mathrm{O}^{1} \mathrm{D}\right)$ are approximately double those shown in the original investigation using the original band settings when no limits are applied to the scaling ratio. This arises from updating the method in which $\phi$ is determined (where the temperature dependent $\sigma$ values originate from Molina and Molina (1986) in both cases). The original quantum yield was taken from the study of Talukdar et al. (1998), whereas the one adopted here was based on the recommendation of Matsumi et al. (2002), which is a critical synthesis of many independent studies. This update leads to substantial differences especially in the contribution made by the fourth band to $J_{\mathrm{O}_{3}}\left(\rightarrow \mathrm{O}^{1} \mathrm{D}\right)$ and, more importantly, the contribution to the total $J$ value made by each wavelength bin (not shown). From this it maybe concluded that the errors associated with the band method are critically dependent on the input parameters used to determine the individual photolysis rates. Therefore, it should be noted that any future updates may affect the absolute values of the associated errors presented here.

The effect of ground albedo on the resulting errors was tested for those photolysis rates which are most important near to the ground, as this is where the largest perturbation of the radiative flux occurs due to enhanced reflection. For all instances the surface was assumed to behave as a Lambertian Reflector. It was found that the performance of the modified band approach is fairly robust across the range of ground albedos from 0.01 through to theoretical maximum of 1.0, and, in general, the errors remain rather constant for the chemical species contained in the tropospheric subset. Therefore, it can be concluded that the modified band approach can be used with confidence over a diverse range of reflecting surfaces.

Finally, as a means of testing the sensitivity of the band method to the variation in the total overhead $\mathrm{O}_{3}$ column (i.e. optical depth) duplicate calculations were performed using 

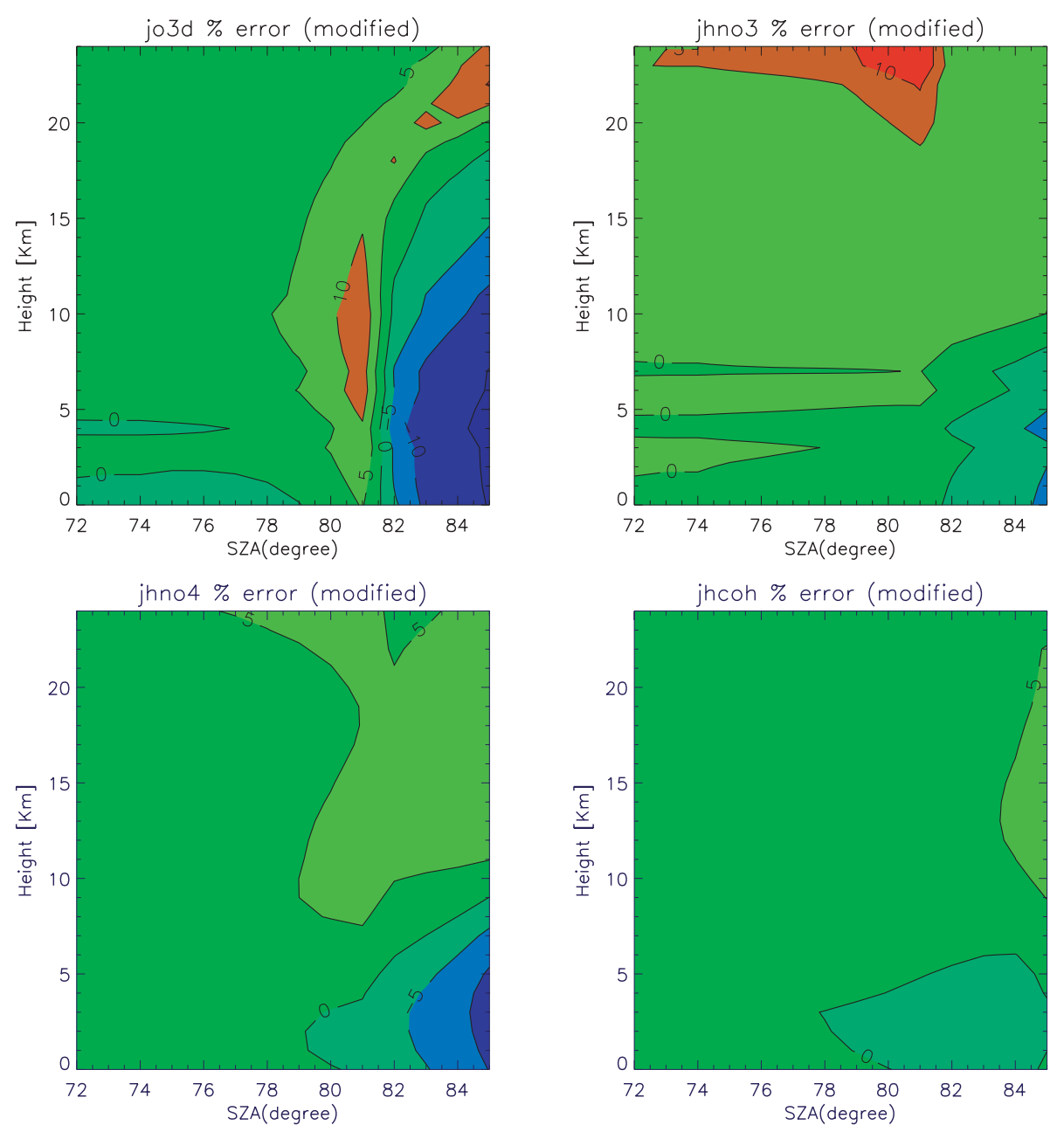

Fig. 14. The variation in the error budgets associated with the $J$ values calculated using the modified band approach with grid A in the presence of tropospheric aerosol for (a) $\mathrm{O}_{3} \rightarrow \mathrm{O}^{1} \mathrm{D}$ (b) $\mathrm{HNO}_{3}$ (c) $\mathrm{HNO}_{4}$ and (d) $\mathrm{HCOH}$ with respect to the incident $\theta$. Comparisons are made against reference B. The contouring used is identical to Fig. 12 to aid comparison. All other conditions are identical to those described in Sect. 4.2 .

various scaling factors of between 250-400 DU (not shown). No significant change in the distribution of the associated errors compared to those shown for $300 \mathrm{DU}$ were observed, indicating that the performance of the band method is robust over a range of atmospheric conditions.

\subsubsection{Errors for $\theta=85-93^{\circ}$}

For solar zenith angles $>85^{\circ}$, the magnitude of the $F_{\text {act }}$ values in the middle and lower layers of the atmosphere (below $50 \mathrm{~km}$ ) are essentially governed by the diffuse radiation i.e. the $F_{\text {abs }}$ contribution becomes very small. As with solar zenith angles $<85^{\circ}$, this has unwanted numerical consequences in terms of large values for the $\delta_{i}$ ratios calculated for bands 2 through to 4 , which results in unrealistically large $J$ values. Therefore, a limit for the scaling ratios was again applied to the bands 2 through to 4 between $\theta=85-93^{\circ}$. Due to differences in the radiation field as a result of using PIFM-
PS (i.e. an increase in $F_{\text {abs }}$ ), a further set of limits for the $\delta_{i}$ ratios are defined for $\theta>85^{\circ}$ as given in Table 4 . For the tropospheric subset of species, the values for $F_{\text {act }}$ become so small near the surface that the resulting $J$ values become rather unimportant when considering the diurnally integrated rates. Thus, we limit the following discussion to the errors associated with the stratospheric subset of chemical species calculated when using grid $\mathrm{B}$, in conjunction with the PIFMPS solver. Figures $13 \mathrm{a}-\mathrm{d}$ show the resulting errors calculated for $J$ values over the range $\theta=85-93^{\circ}$ for a select number of species from the stratospheric chemical subset thought to be the most important for polar chemical ozone depletion at such high incident angles (Lamago et al., 2003). For the range $\theta=85-90^{\circ}$ a resolution of $1^{\circ}$ is used, after which a finer resolution of $0.5^{\circ}$ is adopted to provide more information between $\theta=90-93^{\circ}$. The associated error budgets are generally below $10 \%$ above $30 \mathrm{~km}$ altitude, except where the 
shadowing effect of the earth begins to reduce the $F_{\text {abs }}$ component to such an extent that the application of limits to the scaling ratio is needed. This subsequently introduces larger errors of between $10-30 \%$ at $20-30 \mathrm{~km}$. Moreover, the application of grid B leads to a substantial reduction in the associated errors compared to $J$ values calculated with both the original grid and grid A (not shown). Although it is possible to calculate $J$ values with PIFM-PS up to an incident zenith angle of $95^{\circ}$ (see Sect. 3.2), the small values of both $F_{\text {act }}$ and $F_{\text {abs }}$ result in large errors being introduced at angles above $\theta=93^{\circ}$ for similar reasons to those discussed above. In fact, a significant degradation in the performance can be seen for $\theta>92.5^{\circ}$, suggesting this limit should be applied online. Moreover, many of the $J$ values become so small under such conditions that the computational expense of performing the calculation is often not warranted.

\subsection{Clear-sky with tropospheric aerosol}

In global CTMs clear-sky conditions almost never exist due to the ubiquitous presence of aerosols, liquid water clouds and ice water clouds (with the cloud fraction, liquid water content and ice water content usually being defined by the meteorological input data). The effect of both clouds and aerosol on atmospheric processes via the perturbation of the radiation field has been extensively discussed in the literature (e.g. He and Carmichael, 1999; Haywood and Boucher, 2000; Tie et al., 2004). Here we investigate the effects that aerosol particles have on the error budgets associated with the $J$ values calculated with the modified band approach. For brevity we only present the results calculated using grid A for a few species selected from the tropospheric subset, which are thought to be the most sensitive. The simulations are performed using rural aerosol for the lowest $4 \mathrm{~km}$ and 'background' aerosol for the rest of the model atmosphere. The particle number density of each layer was scaled such that the integrated optical depth due to the aerosol column was 0.32 at $550 \mathrm{~nm}$, in line with the settings chosen in Landgraf and Crutzen (1998). Figure 14 shows the effect of aerosol loading on the error budgets associated with the $J$ value profiles calculated for $\mathrm{O}_{3} \rightarrow \mathrm{O}^{1} \mathrm{D}$, (b) $\mathrm{HNO}_{3}$, (c) $\mathrm{HNO}_{4}$ and (d) $\mathrm{HCOH}$. For this purpose comparisons are made against $J$ value profiles calculated using reference model B. Comparing these contour plots with the corresponding plots given in Fig. 12 shows that the contouring is approximately the same for these chemical species. Therefore, the additional absorption and scattering introduced by tropospheric aerosol does not result in any significant degradation in the performance of the modified band approach.

For the "urban" aerosol, as defined by Shettle and Fenn (1979), which exhibits a higher absorption component than the "rural" aerosol, there is a larger reduction in the $J$ values for the bottom layers compared to those obtained using "rural" aerosol (not shown). However, the effect on the error budgets is again minimal, meaning that no significant differences exist compared to the error contours shown in Fig. 14.

\subsection{Cloudy atmosphere}

The final analysis presented in this paper focuses on effects of cloud on the error budget of the modified band approach. For this purpose we consider a model atmosphere with two cloud layers each having $100 \%$ cloud coverage at $1-2 \mathrm{~km}$ and $7-8 \mathrm{~km}$ with optical densities of 24.9 and 38.3 , respectively. The aerosol loading is prescribed as in Sect. 4.2 but we assume that the relative humidity within the cloud layers is near saturation $(98 \%)$. Due to the increase in relative humidity in the cloud layer the aerosol optical depth increases to 0.52 at $550 \mathrm{~nm}$. Such conditions pertain to the type of scenarios commonly encountered in a CTM. For the tropospheric species the effect of cloud on the $J$ values is similar to that shown in Landgraf and Crutzen (1998), and is briefly summarized here. The attenuation of light directly above the highest cloud layer (at 7-8 km) causes a substantial increase in the magnitude of the $J$ values at the cloud top ( $\sim 50 \%)$. This amplification gradually disappears with altitude until the $J$ values are approximately equal to clear sky conditions at $\sim 20 \mathrm{~km}$ altitude. There is a corresponding decrease directly below the cloud layer $(\sim 20 \%)$, which again gradually disappears at altitudes of $2-3 \mathrm{~km}$. The lower cloud layer effectively screens the lowest layers resulting in decreases in the certain $J$ values of upto $\sim 80 \%$. Those species which absorb below $\lambda<320 \mathrm{~nm}$ are the most affected due to the importance of enhanced scattering in the UV spectral region.

Figure 15 shows the effect both cloud and aerosol has on the error budgets associated with the $J$ values calculated for the chemical species shown in Fig. 14. Although there is a re-distribution and, in some instances, a change in the associated error budgets for a few of the species shown the resulting errors are generally still within $\pm 10 \%$ in the lower $10 \mathrm{~km}$, even though the optical density of the column increases significantly. Moreover, it should be noted that this result pertains to a worst-case scenario of $100 \%$ cloud coverage. In a CTM the majority of grid cells have smaller cloud fractions and thus, smaller changes in the associated errors compared to the full-cloud scenario. It should be noted that for $\theta>85^{\circ}$ clear-sky conditions are assumed in PIFM-PS during the RT calculations due to the numerical instability introduced in the lower layers for combinations of long slant paths and layers with high optical depths due to abnormally high $\tau_{\text {slant }}$ values.

Figure 16 shows the corresponding results for the stratospheric species included in Fig. 11. Comparison of these plots shows that the effect of the increase in upwelling radiation is rather insignificant. However, it should be noted that the $J$ values for more sensitive species (e.g. $\mathrm{NO}_{2}$ ) can be altered by this effect (not shown).

In summary, no significant degradation in the accuracy of the band method occurs for cloudy conditions for chemical 

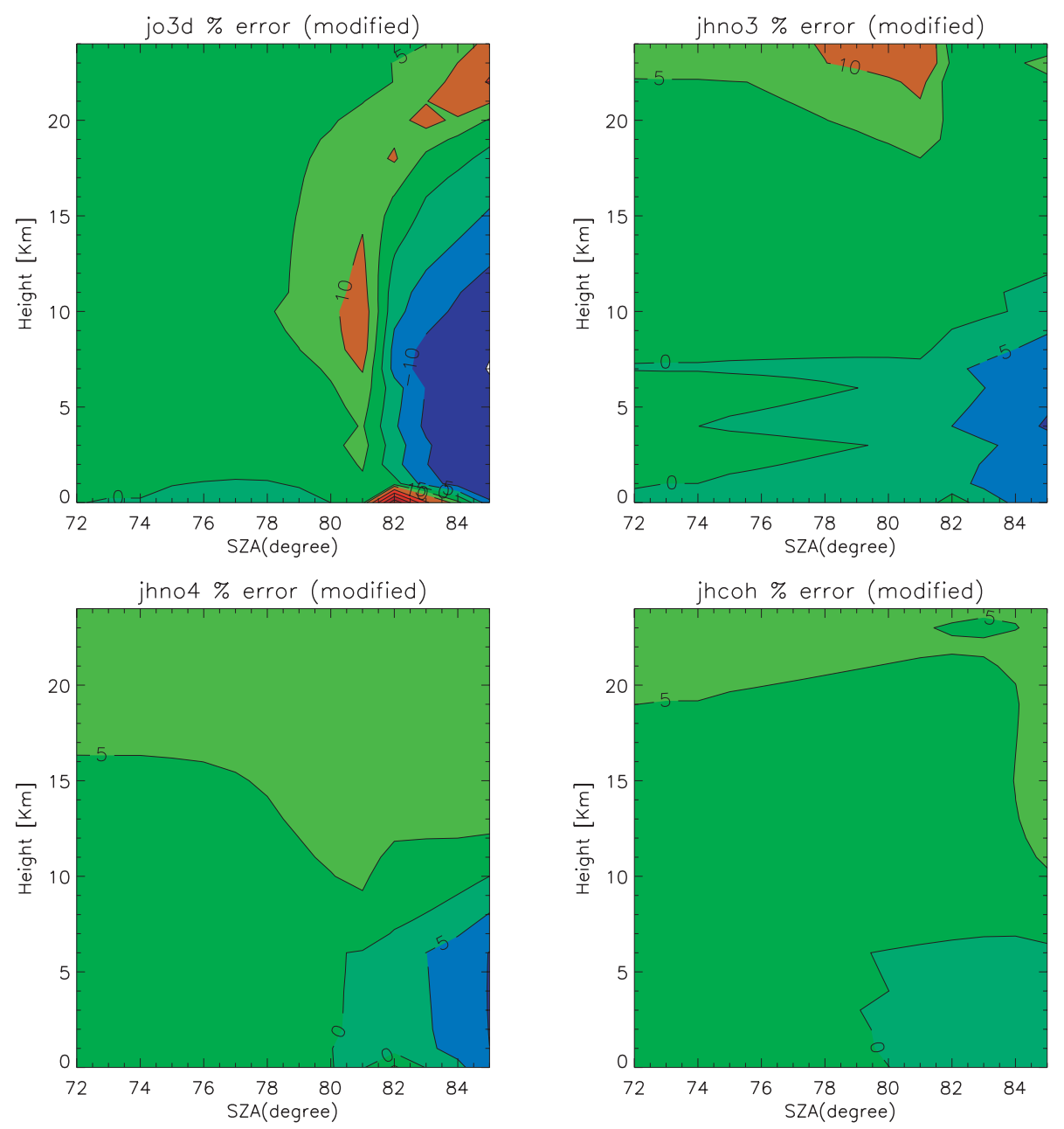

Fig. 15. The variation in the error budgets associated with the $J$ values calculated using the modified band approach with grid A in the presence of cloud and aerosol for (a) $\mathrm{O}_{3} \rightarrow \mathrm{O}^{1} \mathrm{D}$ (b) $\mathrm{HNO}_{3}$ (c) $\mathrm{HNO}_{4}$ and (d) $\mathrm{HCOH}$ with respect to the incident $\theta$. Comparisons are made against reference B. The contouring used is identical to Fig. 12 to aid comparison. All other conditions are identical to those described in Sect. 4.2.

species which are photolytically important for both the troposphere and the stratosphere.

\section{Further discussion}

\subsection{Other chemical species}

For the $J$ values calculated for the additional chemical species to those listed in Table 3 there are corresponding improvements in the accuracy of the modified band method using both grids $\mathrm{A}$ and $\mathrm{B}$ compared to the original default settings. These remaining species include $\mathrm{CH}_{3} \mathrm{OOH}$, PAN, $\mathrm{CH}_{3} \mathrm{CHO}, \mathrm{CH}_{3} \mathrm{COOH}, \mathrm{CH}_{3} \mathrm{O}_{2} \mathrm{NO}_{2}, \mathrm{CH}_{3} \mathrm{Cl}, \mathrm{CH}_{3} \mathrm{Br}, \mathrm{HCl}$, CFC11, CFC113, $\mathrm{HOCl}, \mathrm{HOBr}, \mathrm{CH}_{3} \mathrm{COCHO}, \mathrm{CH}_{3} \mathrm{COCH}_{3}$ and $\mathrm{NO}_{3}$ and may be sub-divided into those species which are photolytically important for either the troposphere or the stratosphere.
For the zenith angle range $\theta=72-85^{\circ}$, the additional stratospheric species generally exhibit a reduction in the associated errors above $30 \mathrm{~km}$ using grid $\mathrm{A}$ for clear-sky conditions compared with the original method (namely $J_{\mathrm{CH}_{3} \mathrm{O}_{2} \mathrm{NO}_{2}}$, $J_{\mathrm{CFC} 11}, J_{\mathrm{CFC} 113}, J_{\mathrm{CH}_{3} \mathrm{Cl}}, J_{\mathrm{CH}_{3} \mathrm{Br}}, J_{\mathrm{HOCl}}$ and $J_{\mathrm{HOBr}}$ ). Below this height there is an increase in the associated error for most of these $J$ values, although in many instances the $J$ values are unimportant at such low altitudes. For the additional tropospheric species, again, a reduction in the associated error

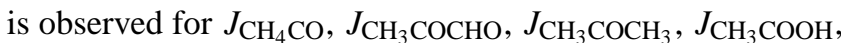
$J_{\mathrm{PAN}}$ and both channels of $J_{\mathrm{NO}_{3}}$. The most dramatic reductions in error occur for those species which exhibit large contributions from band 4 (e.g. $\mathrm{CH}_{3} \mathrm{COCH}_{3}$ ). Another notable example is the photolysis of $\mathrm{NO}_{3}$ which falls to $\pm 3 \%$ in the lowest $10 \mathrm{~km}$ compared to $-5-10 \%$ obtained using the original band settings. The only exception to this trend is a small increase in error for $\mathrm{J}_{\mathrm{O} 3}\left(\rightarrow \mathrm{O}^{3} \mathrm{P}\right)$ (reaching $\sim 8 \%$ compared 

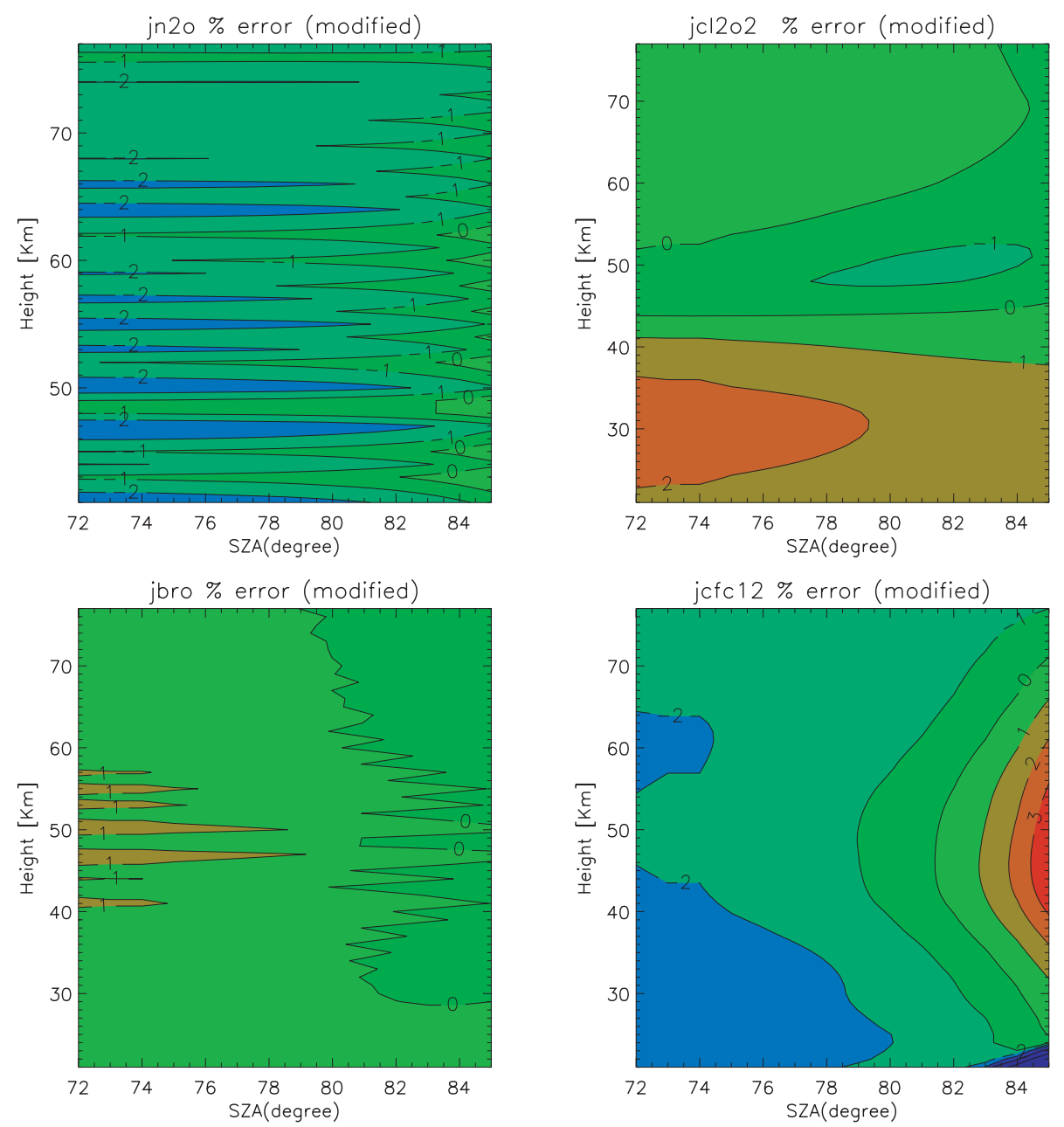

Fig. 16. As for Fig. 15 except plots are shown for (a) $\mathrm{N}_{2} \mathrm{O}$, (b) $\mathrm{Cl}_{2} \mathrm{O}_{2}$, (c) $\mathrm{BrO}$, and (d) $\mathrm{CFC} 12$ with respect to the incident $\theta$ for the middle and upper atmosphere.

with $\sim 3 \%$ for the lowest few layers of the atmosphere).

For scenarios which include cloud and aerosols, there are similarities in the change in the distribution of the error budgets as those discussed in Sect. 4.3. Associated errors of between 5-10\% exist from 0-25 km for all the additional tropospheric species except $J_{\mathrm{CH}_{4} \mathrm{CO}}$, which has similar band contribution as for $J_{\mathrm{O}_{3}}\left(\rightarrow \mathrm{O}^{1} \mathrm{D}\right)$ and thus exhibits an increase in the lowest layer at $\theta=82^{\circ}$. For the additional stratospheric species there is only a minimal effect on the associated errors compared to the clear-sky scenario discussed above, similar to the differences shown between Figs. 11 and 16.

\subsection{The feasibility of future updates}

The photolysis scheme presented here has been specifically designed to calculate height resolved $J$ values for chemical species which are photolytically important to the chemical composition of the troposphere and stratosphere. Therefore, if one wished to use such a scheme for a model which focuses purely on the troposphere, where the photolysis of species such as, for example, the CFC's and $\mathrm{N}_{2} \mathrm{O}$ are not important, then modifications could be made to the approach (e.g. the removal of band 1). It should be noted that for any additional species the associated error depends on which bands contribute to the final $J$ value. Chemical species with absorption maxima at $\lambda>305.5 \mathrm{~nm}$ will have rather small associated errors, such as e.g. dimethyl sulfide (DMS). Moreover, new values for the photolytic parameters $\left(\sigma_{x}\right.$ and $\left.\phi_{x}\right)$ can be easily implemented into the scheme due to the transparent nature in which the scheme has been designed (i.e.) by simply updating the look-up table by interpolating the updated values onto the working grid.

The application of the pseudo-spherical approximation to the two-stream method adopted in this work for high zenith angles should be considered to be a pragmatic way in which to improve twilight photolysis rates when the use of more complex RT solvers is not feasible. The band approach has a limitation in that the performance depends on the use of a 
relative fine spectral grid. In order to allow the online use of an 8-stream solver in a 3-D CTM requires one to adopt a much coarser spectral grid (Bian and Prather, 2002; Tie at al, 2004). However, in atmospheric models which have lower computational overheads, the modified band approach adopted here could be used in tandem with either a 4- or 8stream solver which would reduce the error contribution due to the solver. Moreover, considering that computational resources are increasing, it should be feasible to make this step in large global transport models at a future date, depending on the allocation of the total run-time to the different processes occurring in the model.

\subsection{Analysis of efficiency}

In order to provide some idea of the efficiency of the modified band approach we have analysed some typical runtimes obtained using the "final working version" for a variety of different zenith angles, where comparisons are made against reference model B. For $\theta<85^{\circ}$ the runtime decreases by $\sim 70 \%$, where $\sim 15 \%$ is due to the use of a look-up table for the temperature dependent absorption properties and the remaining $\sim 55 \%$ is due to the use of the band approach. For $\theta>85^{\circ}$ the associated decrease in runtime falls to $\sim 37 \%$ as a consequence of the increase in the computational burden introduced by calculating the effects of sphericity on both $F_{\text {abs }}$ and $F_{\text {act }}$. Moreover, comparing two runtimes for calculations performed using the band approach at zenith angles above and below $\theta=85^{\circ}$ reveals that there is an increase in runtime of $\sim 200 \%$. A large fraction of this increase originates from the method used to calculate $F_{\text {abs }}$ during the calculation of $J_{\mathrm{abs}}$ across all wavelength bins of the working spectral grid, rather than from the calculation of $F_{\text {act }}$ in the PIFM-PS solver, which only needs to be performed for 8 wavelength bins. This highlights the reason why the use of the sphericity component should be limited to instances where there is a substantial improvement in the resulting $J$ values (i.e.) for $\theta>85^{\circ}$. In summary, the use of the "final working version" results in significant reductions in the computational effort needed for the calculation of height resolved $J$ values for the entire range of zenith angles used in this study.

\section{Conclusions}

In this paper we have presented a flexible, efficient and accurate scheme for the online calculation of height resolved photolysis rates for zenith angles in the range $72-93^{\circ}$, which has been designed specifically for the implementation into both global Chemistry Transport Models and General Circulation Models. For this purpose, we have extended the band method of Landgraf and Crutzen (1998) for $\theta>72^{\circ}$. The result is an enhanced performance in instances of low sun for a diverse range of chemical species.
For $\theta>85^{\circ}$ we have made use of a pseudo-spherical extension of a two-stream radiative transfer solver, PIFM (Zdunkowski et al., 1980). This results in a significant reduction in the errors as compared against a full spherical reference model. The errors on the resulting $J$ values are generally of the order of $\pm 2 \%$ for the middle and upper atmosphere. These increase up to $\pm 40 \%$ below $20 \mathrm{~km}$ for certain species (notably $\mathrm{O}_{3}$ and $\mathrm{HNO}_{4}$ ) although the magnitude of such rates at these high zenith angles is so small that the effect of such errors on the chemical tracer fields is minimal.

For the band method we have introduced modifications which significantly improve the accuracy of the approach, these being: (i) the use of limits on the scaling ratios used for the calculation of the $J$ values, (ii) the use of a scaling ratio for the far UV (band 1) which accounts for the reduced direct flux for $\theta>72^{\circ}$ and (iii) the definition of two additional sets of optimized band parameters (for the thresholds $\theta=72-85^{\circ}$ and $\theta=85-93^{\circ}$, respectively)

In general, the errors introduced by the modified band method are in the region of $\pm 10 \%$ or lower over the range $\theta=72-85^{\circ}$ for species relevant to both the troposphere and the stratosphere. This dramatically improves the performance of the band method compared to the original approach, especially for species such as $\mathrm{O}_{3}$ and $\mathrm{HNO}_{3}$ in instances where the $\theta>80^{\circ}$. For instances where $\theta>85^{\circ}$, the effects of spherical geometry on the direct beam are accounted for, in conjunction with the use of a characteristic set of band parameters and limits on the scaling ratios for bands 2 through to 4 , which results in associated errors to be of the order of $0-10 \%$ between $30-80 \mathrm{~km}$ for many important stratospheric species. The associated errors increase with the incident zenith angle due to the loss of the direct beam in the middle atmosphere. However, many $J$ values become so small in these layers for high zenith angles that this increase in error does not have important consequences.

Finally, we have tested the performance of the modified band method in the presence of both cloud and aerosols, and over a wide range of ground albedo's and total overhead $\mathrm{O}_{3}$ column densities, and subsequently shown that the method is both robust and accurate over a range of conditions typically found in the atmosphere.

Acknowledgements. J. E. W. acknowledges financial support from the European Commission Sixth Framework program SCOUT-O3 (505390-GOCE-CT-2004). A. B. acknowledges financial support from the National User Support Programme run by the Netherlands User Support Programme (GO2(EO-066)). We thank the anonymous reviewers for their suggestions on improving the manuscript.

Edited by: R. Sander

\section{References}

Allen, M. and Frederick, J. E.: Effective photodissociation cross sections for molecular oxygen and nitric oxide in the SchumannRunge bands, J. Atmos. Sci., 39, 2066-2075, 1982. 
Atkinson, R., Baulch, D. L., Cox, R. A., Hampson Jr., R. F., Kerr, J. A., Rossi, M. J., and Troe, J.: Evaluated kinetic and photochemical data for atmospheric chemistry, Supplement V, J. Phys. Chem. Ref. Data., 26(3), 521-1011, IUPAC Subcommittee in Gas Kinetic Data Evaluation, 1997.

Atkinson, R., Baulch, D. A., Cox, R. A., Crowley, J. N., Hampson Jr., R. F., Hynes, R. G., Jenkin, M. E., Kerr, J. A., Rossi, M. J., and Troe, J.: Summary of evaluated kinetic and photochemical data for atmospheric chemistry, IUPAC Subcommittee in Gas Kinetic Data Evaluation, Web Version, http://www.iupac-kinetic. ch.cam.ac.uk, 2004.

Balluch, M. and Lary, D. J.: Refraction and atmospheric photochemistry, J. Geophys. Res., 102, 8845-8854, 1997.

Bian, H. and Prather, M. J.: Fast-J2: Accurate simulations of Stratospheric Photolysis in Global Chemical Models, J. Atmos. Chem., 41, 281-296, 2002.

Brasseur, G. P., Hauglustaine, D. A., Walters, S., Rasch, P. J., Muller, J.-F., Granier, C., and Tie, X.: MOZART, a global chemical tracer model for ozone and related chemical tracers. 1. Model description, J. Geophys. Res., 103, 28 265-28 289, 1998.

Bregman, A., Lelieveld, J., van den Broek, M. M. P., Siegmund, P. C., Fischer, H., and Bujok, O.: $\mathrm{N}_{2} \mathrm{O}$ and $\mathrm{O}_{3}$ relationship in the lowermost stratosphere: a diagnostic for mixing processes as represented by a three-dimensional chemistry-transport model, J. Geophys. Res., 105, 17 279-17 290, 2000.

Brühl, C. and Crutzen, P. J.: Scenarios of possible changes in atmospheric temperatures and ozone concentrations due to man's activities, estimated with a one-dimensional coupled photochemical climate model, Climate Dyn., 2, 173-203, 1988.

Caudill, T. R., Flittner, D. E., Herman, B. M., Torres, O., and McPeters, R. D.: Evaluation of the pseudo-spherical approximation for backscattered ultraviolet radiances and ozone retrieval, J. Geophys. Res., 102, 3881-3890, 1997.

Chabrillart, S. and Kockarts, G.: Simple parameterization of the absorption of the solar Lyman-Alpha line, Geophys. Res. Lett., 24(21), 2659-2662, 1997. Also: Correction: Geophys. Res. Lett., 25(1), 79, 1998.

Chandraesekhar, S.: Radiative Transfer, Dover Publications. Inc., New York, 1960.

Doicu, A., Trautmann, T, Schreier, F., and Hess, M.: Finite element method for the two-dimensional atmospheric radiative transfer, J. Quant. Spectrosc. Radiat. Transfer, 91, 347-361, 2005.

Geleyn, J. F. and Hollingsworth, A.: An Economical analytical method for the computation of the interaction between scattering and line absorption of radiation, Contrib. Atms. Phys., 52(1), 1-16, 1979.

Goody, R. M. and Yung, Y. L.: Atmsopheric Radiation: Theoretical Basis, Oxford University Press, New York, 1989.

Haywood, J. and Boucher, O.: Estimates of the direct and indirect radiative forcing due to tropospheric aerosols: a review, Rev. Geophys., 38, 513-543, 2000.

He, S. and Carmicheal, G. R.: Sensitivity of photolysis rates and ozone production in the troposphere to aerosol properties, J. Geophys. Res., 104, 26 307-26 324, 1999.

Karsten, F. and Young, A. T.: Revised optical air mass tables and approximation formula, Appl. Opt., 28, 4735-4738, 1989.

Koch, S. and Moortgat, G. K.: Photochemistry of Methylglyoxal in the vapour phase, J. Phys. Chem. A, 102, 9142-9153, 1998.

Koppers, G. A. A. and Murtagh, D. P.: Model studies of the influence of $\mathrm{O}_{2}$ photodissociation parameterizations in the Schumann-Runge bands on ozone related photolysis in the upper atmosphere, Ann. Geophys., 14, 68-79, 1996, http://www.ann-geophys.net/14/68/1996/.

Kouker, W., Langbein, I., Reddmann, T., and Runke, R.: The Karlsruhe Simulation Model of the Middle Atmosphere (KASIMA), Version 2, Forsch. Karlsruhe, Wiss. Ber. No. 6278, Karlsruhe, Germany, 1999.

Kylling, A., Stamnes, K., and Tsay, S.-C.: A reliable and efficient two-stream algorithm for spherical radiative transfer: Documentation of accuracy in realistic layered media, J. Atmos. Chem., 21, 115-150, 1995.

Lamago, D., Dameris, M., Schnadt, C., Eyring, V., and Brühl, C.: Impact of large solar zenith angles on lower stratospheric dynamical and chemical processes in a coupled chemisty-climate model, Atms. Chem. Phys., 3, 1981-1990, 2003.

Landgraf, J. and Crutzen, P. J.: An Efficient Method for online calculations of Photolysis and Heating Rates, J. Atmos. Sci., 55, 863-878, 1998.

Lawrence, M., Crutzen, P. J., Raesch, P. J., Eaton, B. E., and Mahowald, N. M.: A model for studies of tropospheric photochemistry: Description, global distributions and evaluation, J. Geophys. Res., 104(D21), 26 245-26277, 1999.

Lenoble, J.: Radiative transfer in scattering and absorbing atmospheres: standard computational procedures, Deepak, 1985.

Lenoble, J.: Atmospheric Radiative Transfer, Deepak, p. 532, 1993.

Liou, K. N.: An Introduction to Atmospheric Radiation, Academic Press, p. 31, 2002.

Madronich, S.: Photodissociation in the atmosphere: 1. Actinic Flux and the effect of ground reflections and clouds, J. Geophys. Res., 92, 9740-9752, 1987.

Madronich, S. and Weller, G.: Numerical integration errors in calculated tropospheric photodissociation rate co-efficients, J. Atmos. Chem., 10, 289-300, 1990.

Matsumi, Y., Comes, F. J., Hancock, G., Hofzumahus, A., Hynes, A. J., Kawasaki, M., and Ravishankara, A. R.: Quantum yields for production of $\mathrm{O}\left({ }^{1} D\right)$ in the ultraviolet photolysis of ozone: Recommendation based on evaluation of laboratory data, J. Geophys. Res., 107(D3), 4024, doi:10.1029/2001JD000510, 2002.

McClatchey, R. A., Fenn, R. W., Selby, J. E. A., Volz, F. E., and Garing, J. S.: Optical properties of the atmosphere, Environ. Res. Paper, 411, AFCRL-72-0497, p. 108, 1972.

Molina, L. T. and Molina, M. J.: Absolute absorption cross sections of ozone in the 185 to $350 \mathrm{~nm}$ wavelength range, J. Geophys. Res., 91, 14 501-14 508, 1986.

Nicolet, M.: On the molecular scattering in the terrestrial atmosphere : an empirical formula for it's calculation in the homosphere, Planet. Space. Sci., 32, 1467-1468, 1984.

NOAA, US Standard Atmosphere, 1976 National Oceanic and Atmospheric Administration NOAA-S/T76-1562, Washington D.C., U.S. Gov. Printing office, 227, 1976.

Rozanov, A., Rozanov, V., and Burrows, J. P.: Combined differential-integral approach for the radiation field computation in a spherical shell atmosphere: non-limb geometry, J. Geophys. Res., 105, 22 937-22 943, 2000.

Rozanov, A., Rozanov, V., and Burrows, J. P.: A numerical radiative transfer model for a spherical planetary atmosphere: combined differential-integral approach involving the picard iterative approximation, J. Quant. Spectrosc. Radiat. Transfer, 69, 491-512, 
2001.

Sander, S. P., Friedl, R. R., Ravishankara, A. R., Golden, D. M., Kolb, C. E., Kurylo, M. J., Huie, R. E., Orkin, V. L., Molina, M. J., Moortgart, G. K., and Finlayson-Pitts, B. J.: Chemical Kinetics and Photochemical Data for Use in Atmospheric studies, Evaluation No. 14, JPL Publication 02-25, 2003.

Schemansky, D. E.: $\mathrm{CO}_{2}$ Extinction Co-efficient 1700-3000 A, J. Chem. Phys., 56, 1582-1587, 1972.

Shettle, E. P. and Fenn, R. W.: Models for the aerosols of the lower atmosphere and the effects of the humidity variations on their optical properties, Environ. Res. Paper, 676, AFGL-TR-79-0114, 91pp., 1979.

Slingo, A.: A GCM parameterization for the shortwave radiative properties of water clouds, J. Atmos. Sci., 46, 1419-1427, 1989.

Spur, R. J. D., Kurosu, T. P., and Chance, K. V.: A linearized discrete ordinate radiative transfer model for atmospheric remotesensing retrieval, J. Quant. Spectrosc. Radiat. Transfer, 68, 698735, 2001.

Stamnes, K., Tsay, S.-C., Wiscombe, W., and Jayaweera, K.: Numerically stable algorithm for discrete-ordinate-method radiative transfer in multiple scattering and emitted layered media, Appl. Opt., 27, 2502-2509, 1988.
Talukdar, R. K., Longfellow, C. A., Gilles, M. K., and Ravishankara, A. R.: Quantum yields of $\mathrm{O}\left({ }^{1} \mathrm{D}\right)$ in the photolysis of ozone between 289 and $329 \mathrm{~nm}$ as a function of temperature, Geophys. Res. Lett., 25, 143-146, 1998.

Tie, X., Madronich, S., Walters, S., Zhang, R., Rasch, P., and Collins, W.: Effect of clouds on photolysis and oxidants in the troposphere, J. Geophys. Res., 108, 4642, doi:10.1029/2003JD003659, 2003.

Trentmann, J., Bovensmann, H., Eyring, V., Muller, R. W., and Burrows, J. P.: Impact of Accurate Photolysis Calculations on the simulation of Stratospheric chemistry, J. Atmos. Chem., 44, 225-240, 2003.

Walter, H. H., Landgraf, J., and Hasekamp, O.: Linearization of a pseudo-spherical vector radiaitive transfer model, J. Quant. Spectrosc. Radiat. Transfer, 85, 251-283, 2004.

Wild, O., Zhu, X., and Prather, M. J.: Fast-J: Accurate simulation of in- and below-cloud photolysis in global chemical models, J. Atmos. Chem., 43, 245-282, 2000.

Zdunkowski, W. G., Welsch, R. M., and Korb, G. J.: An investigation of the structure of typical 2-stream methods for the calculation of solar fluxes and heating rates in clouds, Contrib. Atms. Phys., 53, 215-238, 1980. 